\title{
Poroelasticity: Finite Element modelling of anomalous tilt and pore pressure caused by pumping in a sedimentary half space with fault
}

\author{
Morelia Urlaub ${ }^{\mathrm{a}, \mathrm{b}, *}$, Marcus Fabian ${ }^{\mathrm{a}, \mathrm{c},}$ \\ ${ }^{a}$ Universität Bremen, Fachbereich Geowissenschaften, Meerestechnik/Sensorik, \\ Klagenfurter Strasse, 28359 Bremen, Germany \\ ${ }^{b}$ now at: National Oceanography Centre, Southampton, European Way, Southampton \\ SO14 3ZH, United Kingdom \\ ${ }^{c}$ now at: Federal Ministry for the Environment, Nature Conservation and Nuclear Safety \\ - Federal Supervision of Nuclear Power Plants, Fundamental Aspects of Nuclear Safety, \\ Robert-Schuman-Platz 3, 53175 Bonn, Germany
}

\begin{abstract}
Extraction of groundwater or hydrocarbons causes pore pressure gradients and soil deformation due to poroelastic coupling. Recent studies show that high-resolution engineering tiltmeters installed at shallow depth between $2-10 m$ resolve this deformation. Models using poroelasticity can describe the relationship between fluid extraction, pore pressure gradients and induced tilt for homogeneous and layered sedimentary half spaces. Faults intersecting a stack of sedimentary layers, for example in the Lower-Rhine-Embayment, are of fundamental impact to the groundwater flow system of an area. However, the fault's hydromechanical effect on pump induced tilt and the pore pressure regime is still poorly investigated. We chose a comparatively simple approach to quantify anomalous pump induced tilt and pore pressure
\end{abstract}

\footnotetext{
*Corresponding author

Email addresses: m.urlaub@noc.soton.ac.uk (Morelia Urlaub), marcus.fabian@bmu.bund.de (Marcus Fabian) 
observed near a fault and close to the surface in a sedimentary subsoil. A PC-based Finite Element software is used to model poroelastic deformation, i. e. modelling vertical tilt and excess pore pressure in response to fluid extraction through a singular well. We compare numerical solutions for models with and without faults and show that a fault can modify symmetry and amplitude of the deformation field by more than a magnitude. We conclude that tilt and pore pressure measurements also at shallow depth can thus be biased by large subsurface structures like faults. Vice versa, these measurements may provide means to quantify hydromechanical effects caused by subsurface structures. However, depending on the geological setting, i. e. if pathways are established by a fault, the anomaly caused by the fault can also be small and hard to detect. Therefore, faults and geological structures like material boundaries have to be considered in poroelastic models carefully. For tilt surveys with a limited number of instruments in geologically well constrained areas these models allow the preselection of potential positions for tiltmeters where prominent field anomalies are expected.

Keywords: deformation, fault, poroelasticity, pore pressure, sedimentary basin, tilt

\section{1. Introduction}

2 Surface deformation caused by subsurface fluid flow and pore pressure gra3 dients was recently observed by high-resolution engineering tiltmeters (0.01 4 to $1 \mu \mathrm{rad}$ resolution) installed at shallow depths or at the surface on land 5 by Lehmann [1], Vasco et al. [2], Fabian [3], Chen [4] and at the sea floor 6 by Tolstoy et al. [5], Fabian and Villinger [6]. The tilt data provide key 
7 information on geological setting, fluid regime, coupling between pore fluid and soil matrix as well as subsidence. Thus, these tiltmeter surveys are commonly conducted in hydrocarbon or groundwater exploration and monitoring $[7,8,2,9]$. In contrast to methods such as optical instrument levelling surveys, global positioning system (GPS) surveys or satellite-related interferometric synthetic aperture radar (InSAR) techniques, which estimate areal 3 surface deformations, tiltmeter surveys are not affected by plant cover, the 14 instruments can be deployed so that they are protected from vandalism and continuous data acquisition is conducted at selected positions with a comparatively high resolution. In addition to the previously named investigations, where tiltmeters are installed in the very upper soil, are studies of Jentzsch and Koss [10], Weise et al. [11], Jahr et al. [12] and Gebauer et al. [13] which focus on long-term surveys and the use of very high resolution tiltmeters (vertical pendulums) installed at depths $>30 \mathrm{~m}$.

Geological structures such as a fault alter the subsurface fluid flow, e.g. anomalous hydraulic head gradients are often associated with faults [14, 15]. Weise et al. [11] and Jahr et al. [16] attribute observed tilt anomalies to the existence of faults. Consequently, questions arise about the nature and amplitude of anomalies caused by a fault. Are these anomalies detectable with field instruments like engineering tiltmeters? To know the potential effect of such subsurface structures is essential not only to correctly interpret field data and to understand fundamental hydrogeological and poroelastic processes, but also for tiltmeter survey designs in areas of prospective groundwater or hydrocarbon exploration.

As the number of instruments in such surveys is often limited, tilt data is 
restricted to selected observation positions [3]. The surface deformation field on top of a reservoir in the vicinity of the surface exposure of a fault is therefore only mapped with an insufficient spatial resolution. The problem would be less critical and a good areal coverage could be achieved if appropriate positions can be selected in advance, based on geological information from the survey area. The recent studies of e.g. Wang and Kümpel [17], Jahr et al. [18] and Kihm et al. [19] successfully model pump induced tilt data using the theory of poroelasticity [20], which describes coupling between pore fluids and soil matrix. However, due to limited computing capacity on desktop PCs, in most cases only simplified 1D-models like a homogeneous or horizontally layered half space could be computed and calculations were mostly done for singular tiltmeter positions at selected depths [3]. Consequently, there is the demand for advanced but easy-to-implement models which, (a) describe the influence of anomalies like faults on the surface deformation field, (b) provide a higher spatial resolution for the complete model domain in order to include prominent subsoil structures and (c) can be set up and computed with a manageable effort, preferably in-situ and on a laptop. Particularly for experimental studies in regions with well-constrained geological settings such as the sedimentary basin of the Lower Rhine Embayment [21, 22] or in areas where intensive geophysical site-surveys were done, such models would allow better placement of tiltmeters, where minima, maxima or any type of prominent signal anomaly of an expected deformation field will occur.

To understand the effect of a vertical boundary on pore pressure, tilt and deformation fields in a subsurface where fluid flow takes place and to provide a model into which local geology can be incorporated and which can 
be run on standard desktop PCs, we use the Finite Element (FE) software Comsol Multiphysics [23] to compute the 3D steady-state deformation field close to a fault caused by fluid extraction from subsoil through a singular well. This study aims on tilt surveys with a duration of several days to weeks or a couple of months as conducted for hydrocarbon or groundwater related purposes $[8,14]$. Usually, 10 to 20 geodetic tiltmeters, e. g. AGI type instruments [24], are installed in shallow boreholes at depth less than $10 \mathrm{~m}$ below the surface. We therefore quantitatively focus on tilt and pore pressure effects observable in the upper $10 \mathrm{~m}$ of the subsurface but also assess larger depths to qualitatively understand deeper processes.

Models are analysed for tilt, pore pressure, pore pressure gradient and deformation fields. At first we give general remarks on the software, explain the implementation of poroelastic equations and validate the software's capability to solve poroelastic problems (section 2). In section 3, the general set up such as geometries, mesh design, boundary conditions and poroelastic parameters of the models used in this study is explained. The effect of a fault on pore pressure, pore pressure gradient, tilt and deformation is analysed on simple models of two adjacent blocks of different materials (section 4). More sophisticated models with different types of faults in typically layered sedimentary subsoils are presented and evaluated in section 5. Section 6 discusses the major results of the presented models with respect to the impact on field studies as well as limitations of the assessment. 


\section{Model Selection}

Models are set up to represent a typical geological setting of a sedimentary basin with large deposits of groundwater. This should allow us to qualitatively compare modelling results with field measurements. For instance, Fig. 1 shows a cross section from the Lower-Rhine Embayment redrawn after Fabian [3]. In such a setting sediment layers form a stack, some hundred meters in depth. The area is flat and the layer-stack is fully saturated with groundwater guided by aquifers at different depths. Wells tapping those aquifers can extract groundwater and cause surface deformation. A fault rising from bedrock and cutting through the sediments can establish a hydraulic barrier, as aquiclude and aquifer layers are offset [25, 26].

FIGURE 01

The simplest model to describe a fault in a sedimentary subsoil is a bare interface between two blocks of distinct material adjacent to each other. However, as simple the model is, it might be used to describe the situation for example in a permeable sedimentary filled valley surrounded by impermeable steep hills. A material contrast of small-grained sand within the block that contains the production well and silt in the neighbouring sediment block, is chosen in order to describe the fault as a barrier. Corresponding poroelastic parameters after Fabian [3] are given in Tab.1. A model of a homogeneous half space consisting of small-grained sand was calculated as a reference. To study a typical sedimentary subsoil with a fault as shown in Fig. 1, a model of a layered half space with four layers is used. Fig. 2 shows the geometries of three different layered models without (Fig. 2(a)) and with a fault (Fig. 2(b, 
c)) that are analysed in this work. The model without a fault is used as a reference. Please refer to Fabian [3] for a detailed analysis of the effect of layers on tilt and pore pressure in a pumped half space. Groundwater is pumped from a confined aquifer of small-grained sand at depths between $-75 \mathrm{~m}$ and $-125 \mathrm{~m}$ (layer 3 ). On top of the aquifer a $45 \mathrm{~m}$ thick aquiclude of a clay layer from $-30 m$ to $-75 m$ (layer 2 ) and an overlying layer of a free aquifer of small-grained sand (layer 1) confine the deeper subsoil. At the models' bottom a clay layer between $-125 m$ and $-200 m$ (layer 4 ) also acts as an aquiclude. The length of the layered models is $1800 \mathrm{~m}$ to allow investigation of pump induced effects at some distance from the well. A $20 \mathrm{~m}$ wide vertical fault zone intersects the model and is located between $x=100 \mathrm{~m}$ and $x=120 \mathrm{~m}$. The block without the well is shifted downwards with an offset of $50 \mathrm{~m}$ to simulate a normal fault. This displacement results in a thickness of the upper free aquifer of $80 \mathrm{~m}$ instead of $30 \mathrm{~m}$ as it is in the block with the well. Two different kinds of fault zones are modelled. Faults in poorly lithified sediments do not provide vertical flow paths [27] and appear as mixing zones of available materials at the grain-scale [28]. Thus, for the model shown in Fig. 2(b) poroelastic parameters of the fault zone within $z=-50 \mathrm{~m}$ and the model's bottom are those of loam, which is less permeable than small-grained sand and higher permeable than clay (compare Tab.1). In the upper part of the fault zone, where no mixing is assumed, poroelastic parameters are those of small-grained sand - as in the upper free aquifers. Accordingly, an observer at the surface would not notice that a fault exists in the subsoil because of no change in soil type. Contrary, the model shown in Fig. 2(c) has a step fracture fault zone: Instead of a 
uniform fault zone running vertically from the bottom to $z=-50 \mathrm{~m}$, the four layers of the formation are offset downwards by two $25 \mathrm{~m}$ steps. The layers of the subsoil block without well are completely displaced with respect to the layers in the block that contains the well, so that fluids crossing the fault to reach the well have to move upwards.

FIGURE 02

All layers are assumed to be fully saturated. Despite the different lengths all models have the same depth $(200 \mathrm{~m})$ and width $(150 \mathrm{~m})$. Poroelastic parameters are as in Tab.1. An overview of all models presented in this work is given in Tab. 2.

\begin{tabular}{|ll|llll|ll|}
\hline label & material & $G[G P a]$ & $\nu$ & $\nu_{u}$ & $B$ & $\alpha$ & $K_{f}[\mathrm{~m} / \mathrm{s}]$ \\
\hline sgs & small- & 0.20 & 0.15 & 0.40 & 0.85 & 0.90 & $1 \cdot 10^{-4}$ \\
& grained sand & & & & & & \\
$\mathrm{s}$ & silt & 0.35 & 0.20 & 0.40 & 0.75 & 0.95 & $5 \cdot 10^{-6}$ \\
$\mathrm{l}$ & loam & 0.50 & 0.20 & 0.40 & 0.75 & 0.95 & $1 \cdot 10^{-7}$ \\
$\mathrm{c}$ & clay & 0.50 & 0.20 & 0.40 & 0.75 & 0.95 & $5 \cdot 10^{-9}$ \\
\hline
\end{tabular}

Table 1: Poroelastic parameters used in this study are taken from Fabian [3]. $G$ is shear modulus, $\nu$ Poisson's ratio, $\nu_{u}$ undrained Poisson's ratio, $B$ Skempton's coefficient, $\alpha$ the coefficient of effective stress and $K_{f}$ is the $K_{f}$-value, which is related to Darcy permeability, fluid density, gravity and dynamic viscosity. 


\begin{tabular}{|c|c|c|c|c|c|}
\hline & \multicolumn{2}{|c|}{ Single Layer } & \multicolumn{3}{|c|}{ Layered } \\
\hline & $\begin{array}{l}\text { Homo- } \\
\text { geneous }\end{array}$ & Interface & $\begin{array}{l}\text { Undis- } \\
\text { turbed }\end{array}$ & Fault zone & Step fracture \\
\hline length in $\mathrm{x}$ & $600 \mathrm{~m}$ & $600 \mathrm{~m}$ & $1800 \mathrm{~m}$ & $1800 \mathrm{~m}$ & $1800 \mathrm{~m}$ \\
\hline fault type & - & $\begin{array}{l}\text { vertical } \\
\text { material } \\
\text { boundary }\end{array}$ & - & $\begin{array}{l}\text { vert. } 20 \mathrm{~m} \\
\text { wide zone } \\
\text { of material } \\
\text { mixture }\end{array}$ & $\begin{array}{l}\text { vert. } \quad 20 \mathrm{~m} \\
\text { wide, step-like } \\
\text { offsets at } \\
\text { boundaries }\end{array}$ \\
\hline $\begin{array}{l}\text { distance } \\
\text { well-fault } \\
\text { in } \mathrm{x}\end{array}$ & - & $\begin{array}{l}100 \mathrm{~m} \\
\left({ }^{* *}\right) 30, \ldots, 150 \\
(*) 70\end{array}$ & - & $100 \mathrm{~m}$ & $100 \mathrm{~m}$ \\
\hline $\begin{array}{l}\text { well depth } \\
\text { in } z\end{array}$ & $-100 \mathrm{~m}$ & $\begin{array}{l}-100 \mathrm{~m} \\
*-20, \ldots,-175\end{array}$ & $-100 \mathrm{~m}$ & $-100 \mathrm{~m}$ & $-100 \mathrm{~m}$ \\
\hline $\begin{array}{l}\text { offset at } \\
\text { fault in } \mathrm{z}\end{array}$ & - & - & - & $50 \mathrm{~m}$ & $50 \mathrm{~m}$ \\
\hline layers & 1 & 1 & 4 & 4 & 4 \\
\hline elements & 48876 & 60270 & 135488 & 138641 & 145350 \\
\hline Figs. & $\begin{array}{l}7 a-b \\
8 a-d\end{array}$ & $\begin{array}{l}4,7 \mathrm{~b}-\mathrm{c}, 8 \mathrm{e}- \\
\mathrm{h}, 9\left(^{*}\right), 10\left({ }^{* *}\right)\end{array}$ & $\begin{array}{l}2 \mathrm{a} \\
11 \mathrm{a}-\mathrm{b}\end{array}$ & $\begin{array}{l}2 \mathrm{~b}, 11 \mathrm{c}-\mathrm{d}, \\
12\end{array}$ & $2 \mathrm{c}, 13,14$ \\
\hline
\end{tabular}

Table 2: Overview of models discussed in this study. All models represent the subsoil down to $-200 \mathrm{~m}$ (z-direction) and account for a width of $150 \mathrm{~m}$ (y-direction). The model type is written in the first line. Given are also specifications in geometry, number of layers, the number of finite elements (discretisation) as well as references to figures, which show the corresponding model.

\section{Poroelastic Modelling}

The FE software package COMSOL Multiphysics is used to solve the fully coupled poroelastic differential equations [20]. The poroelastic equations can be implemented in their coefficient form as two separate equation systems coupled via the pore pressure. Adjusting the 'Stress-Strain Appli- 
cation Mode' gives the elastic part and modifying the 'PDE Module' allows the implementation of the fluid term. Gravity is not considered.

To numerically implement a subsoil setting as shown in Fig. 1, a 3D geometry is required. The well at a certain depth $\mathrm{z}$ with a certain spatial extension of its screen is located at a distance $\mathrm{x}$ in front of the fault, which extends in the $\mathrm{z}$ and $\mathrm{y}$ direction along a plane perpendicular to the focal plane ( $\mathrm{x}-\mathrm{z}$ plane) of Fig. 1. The model domain has a vertical symmetry plane through the centre of the well in the $\mathrm{x}-\mathrm{z}$ plane at $y=0 \mathrm{~m}$. The well, i. e. its screen, is represented by a half-cylinder with a length (in vertical) of $10 \mathrm{~m}$ and a radius (horizontally) of $0.5 \mathrm{~m}$. The screen is centred at $x=0 \mathrm{~m}, y=0 \mathrm{~m}$ and $z=-100 \mathrm{~m}$. Fig. 3 depicts the boundary conditions. The surface at $z=0 \mathrm{~m}$ does not experience traction, i. e. is free to move, and pore pressure is zero. Symmetry at the vertical plane at $y=0 \mathrm{~m}$ implies no normal displacement in this plane as well as no normal flow. Bottom and side boundaries are fixed in their normal direction and pore pressure is set to zero. Note that pore pressure $p$ describes the so called 'excess pore pressure', which is the pump induced part of total pore pressure. It corresponds with the theory of poroelasticity $[29,30]$. Therefore, pore pressure, $p$, vanishes at the outer boundaries as well as at the free surface.

FIGURE 03

Groundwater extraction is simulated at the well screen. The pump rate, $q_{0}$, is the flow $q_{0}=\overrightarrow{v_{f}} \cdot \vec{A}$ through the surface $\vec{A}$ of the well screen and is set to a typical value for water production of $-100 \frac{\mathrm{m}^{3}}{h}$ (Verbandswasserwerk Euskirchen, personal communication, 2000) in all models. $\overrightarrow{v_{f}}=\varkappa \cdot \vec{\nabla} p$ is 
the Darcy velocity in the poroelastic medium with the Darcy conductivity, $\varkappa$. For formulas and boundary conditions at the well screen see Kümpel [29], Hölting [31] and Wang and Kümpel [17].

The FE mesh is designed to have a maximum element edge length of $10 \mathrm{~m}$ at the surface down to $-20 \mathrm{~m}$ depth and $15 \mathrm{~m}$ at all inner interfaces, increasing to $40 \mathrm{~m}$ within the bulk volume (Fig. 4). A maximum length of $5 \mathrm{~m}$ as suggested below (section 3.1) would provide a better estimate of the true solution but computation time is a limiting factor. For a sedimentary subsoil as in the Lower Rhine Embayment, Kümpel et al. [32] conclude that signals from local soil disturbances like soil compaction or swelling of e.g. loam lenses, precipitation or nearby surface loading will only influence tilt measurements close to the surface, if these signals occurred within a distance not larger than $10 \mathrm{~m}$ from the instrument. Moreover, pumping test studies like Kümpel et al. [33], Fabian and Kümpel [34], Fabian [3] show that signals caused by pumping from wells at depths down to $100 \mathrm{~m}$ and deeper can cause strong deformation, tilt and pore pressure changes, which can be observed close to the surface. Because a sedimentary subsoil seems to show a kind of low-pass or high-cut filter character and the focus of this study is on pump induced signals from deeper wells and large structures like faults, we assume with respect to a shorter computing time that a finite element edge length of $10 \mathrm{~m}$ in the upper $20 \mathrm{~m}$ is sufficient. Exclusively quadratic Lagrange elements are applied and direct solvers are used [23]. All models subsequently shown run on a standard desktop PC with a Windows XP Professional x64 operating system, two $1.8 \mathrm{GHz}$ processors and $3.12 \mathrm{~GB}$ of RAM. The computing time for the most complex model (step fracture, Tab. 2 and Fig. 2(c)) is about 
seven hours.

FIGURE 04

\subsection{Software validation}

The algorithm of COMSOL was validated by comparing the software's solution to the analytical solution of Wang and Kümpel [17] for tilt and pore pressure in a homogeneous half space. A half space of small-grained sand with $G=0.2 G P a, \nu=0.15, \nu_{u}=0.4, B=0.85$ and $K_{f}=10^{-4} \frac{m}{s}$ was selected. The well is located at $-100 \mathrm{~m}$ depth with a pump rate of $-100 \frac{\mathrm{m}^{3}}{\mathrm{~h}}$. The maximum finite element edge length is $5 \mathrm{~m}$. We define $\Delta \gamma_{x}$ as tilt in the $\mathrm{x}$ direction and $\Delta \gamma_{y}$ as tilt in the $\mathrm{y}$ direction. The sign convention is according to Wang and Kümpel [17] with the vertical well axis as the origin. A negative sign in tilt indicates subsidence at the surface in the direction towards the well. If not mentioned differently, tilt refers to vertical tilt in the $\mathrm{x}$-direction $\left(\Delta \gamma_{x}\right)$. In Fig. $5(\mathrm{a}, \mathrm{b})$ the tilt and pore pressure fields are rotationally symmetric with respect to the vertical axis through the centre of the well, where tilt is zero (Fig. 5(a)). The tilt field has a butterfly-like pattern. Below the well tilt is negative whereas it is positive above the well. A surface tilt minimum occurs at a radial distance of $1 / \sqrt{2}$ times the well depth from the vertical well axis. This dependency of the position of the surface tilt minimum (or hereafter referred to as absolute maximum) on well depth has been shown by Lehmann [1] and Wang and Kümpel [17]. The maximum's position is, however, independent of poroelastic parameters, which on the other hand determines the amplitude. Tilt is zero between this surface maximum and the upper butterfly-wing pattern. Fig. 5(c, d) shows 
the differences between the analytical and numerical solutions at $-5 \mathrm{~m}$ depth, i. e. exemplary for surface-near tilt and pore pressure. Maximum residuals are $0.02 \mu \mathrm{rad}$ for tilt and $0.17 \mathrm{~Pa}$ for pore pressure. In a homogeneous half space of small-grained sand this corresponds to errors of $0.5 \%$ and $0.004 \%$, respectively. These maximum tilt residuals match the resolution of the best engineering tiltmeters. Pore pressure residuals are even smaller than values that high quality in-situ pressure sensors can detect. In the part of the model domain shown in Fig. 5(e,f) the residuals only exceed $0.02 \mu \mathrm{rad}$ or $5 \mathrm{~Pa}$ near the well. Steep gradients prevail so that in the area with a radius of about $10 \mathrm{~m}$ around the well screen, differences to the analytic solution can become bigger and may be within a range that could be detected by field instruments. FIGURE 05

The model validation also revealed that boundary conditions have a significant impact on the solution. To minimise the effect of boundary conditions we embedded the inner model domain with a fine mesh into a model block of coarse discretisation which should be at least ten times larger (compare Fig. 3). The convergence functions [35] for tilt and pore pressure shown in Fig. 6 prove that the residual between the analytical and numerical solution can be minimised by using smaller elements. A change in slope of the convergence function for tilt occurs where the element length equals $5 \mathrm{~m}$, which we therefore recommend as the ideal element length. However, as computing power is often a limiting factor small differences to the analytical solution remain as depicted in Fig. 5(c-f) and can be attributed to limitations in discretisation. 
FIGURE 06

\section{Interface between two blocks}

In this section we present simple models with the aim to define and understand anomalies in tilt and pore pressure gradient fields that are caused by a vertical material boundary in the vicinity of a pumping well. A homogeneous half space model serves as a reference. The $3 \mathrm{D}$ geometry of the model with material interface can be seen in Fig. 4. Details of the model design can be found in section 3. As in subsequent descriptions, the sediment block that comprises the production well is referred to as block 1 and the sediment block beyond the fault is referred to as block 2 . Block 1 is made of small-grained sand and has a higher permeability as block 2 , which is made of silt. First, vertical x-tilt and excess pore pressure along the symmetry plane at a depth of $-5 \mathrm{~m}$ are described with a focus on location and amplitude of their maxima as well as the position of zero tilt. Subsequently, the pore pressure gradient, the $\mathrm{x}$-tilt field and the direction of deformation is analysed based on a slice through the symmetry plane at $y=0 \mathrm{~m}$. Lastly, anomalies of pore pressure gradient, total tilt field and the direction of deformation in the $\mathrm{x}-\mathrm{y}$ plane at various depths are described. Outstanding features and anomalies are described and sorted according to their importance in terms of field measurements. This order is used for all subsequent model result descriptions.

Fig. 7(a) shows surface tilt $\Delta \gamma_{x}$ along the transect at $y=0 \mathrm{~m}$ as obtained by the numerical solution for a homogeneous half space of small-grained sand 
(reference model). Surface tilt is symmetric to $x=0 m$ where it declines to 0 rad. The strongest amplitudes of $-2.4 \mu \mathrm{rad}$ occur at a radial distance of about $70 \mathrm{~m}$ from the well. This corresponds to $1 / \sqrt{2}$ times the depth of the well screen's centre at $z=-100 \mathrm{~m}$ [1]. In sedimentary basins as illustrated by Fig. 1, pump induced tilt between 0.1 and some $10 \mu \mathrm{rad}$ has been observed depending on the experimental set-up [1,34,3]. Corresponding to Fig. 7(a), Fig. 7(b) delineates the pore pressure gradient at the surface. It is also symmetric to $x=0 \mathrm{~m}$, where a maximum of $0.039 \mathrm{kPa} / \mathrm{m}$ appears. The pore pressure gradient decreases with increasing distance from $x=0 \mathrm{~m}$. Note that at the surface the gradient is not zero, even if pore pressure is zero.

Fig. 7(c) illustrates a vertical $\mathrm{x}-\mathrm{z}$ slice along the symmetry plane $(y=$ $0 \mathrm{~m}$ ). Grey shading reflects the absolute amplitude of the pore pressure gradient field. It decreases logarithmically with increasing distance from the well. Maximum values at the well screen are $40 \mathrm{kPa} / \mathrm{m}$. The black contour lines in Fig. 7 (c) delineate x-tilt, $\Delta \gamma_{x}$, the labels of which are given in $\mu \mathrm{rad}$. The white tilt zero-line represents $0 \mu \mathrm{rad}$. Along this line displacement consists of pure translation (horizontally and/or vertically) so that tiltmeters would not deliver any output signal. At the position of the well a numerical solution is not possible, but contour lines are interpolated by the plotting software. Therefore, this area is shaded off by the grey square. The tilt field has a rotational symmetry with respect to the vertical axis through the centre of the well. A butterfly-like pattern develops around this symmetry axis where $\Delta \gamma_{x}=\Delta \gamma_{y}=0 \mu \mathrm{rad}$. Within the area included by the tilt zeroline, absolute tilt values of up to $6 \mu \mathrm{rad}$ occur near the well, but decline with increasing distance. However, within the tilt zero-line in the upper butterfly 
wings tilt is positive, indicating that the bottom of a tiltmeter would be more attracted towards the well than its top would be, whereas outside of the zero-line tilt is negative. Due to the interference of the free surface deformation with the general deformation pattern of a full space $[1,17]$, the white tilt zero-line only appears in the upper model part. The lower part of the butterfly-like pattern (below $z=-100 \mathrm{~m}$ ) looks wider than the upper one. Black arrows represent the direction of deformation in the $\mathrm{x}-\mathrm{z}$ plane. The model block is mainly deformed in the $\mathrm{z}$ direction with small horizontal components pointing towards the well. Along the well's vertical axis deformation is purely vertical.

Fig. 7(d-f) shows, with the same representations as in Fig. 7(a-c), the numerical solutions for a half space with a fault. The fault is simulated by an interface between two blocks of different unconsolidated sediments at $x=100 \mathrm{~m}$. At the surface (Fig. $7(\mathrm{~d})$ ) strong anomalous tilt appears next to the fault, the strongest amplitude of $-3.5 \mu \mathrm{rad}$ at $x=90 \mathrm{~m}$ is 1.6 times stronger than for the homogeneous half space (Fig. 7(a)). The surface tilt maximum at the other side of the well $\left(\Delta \gamma_{x}=2.6 \mu \mathrm{rad}\right)$, i. e. towards negative $\mathrm{x}$ coordinates, is slightly more pronounced than for the homogeneous half space at nearly the same place. At $x=0 \mathrm{~m}$ surface tilt is not zero as in the homogeneous model but has a value of $-0.1 \mu \mathrm{rad}$. The pore pressure gradient at the surface (Fig. 7(e)) above the well is $0.042 \mathrm{kPa} / \mathrm{m}$ and therewith stronger than in Fig. 7(b). This is also the case for the model part to the right of the well. Contrary, pore pressure gradients of both models are identical at $x=-100 \mathrm{~m}$.

The pore pressure gradient maximum at the well screen in Fig. $7(\mathrm{f})$ is 
$44 \mathrm{kPa} / \mathrm{m}$, about $10 \%$ stronger than for the homogeneous half space in Fig. 7(b). Values decrease radially with increasing distance from the well. Anomalies appear in the vicinity of the fault between $x=95 \mathrm{~m}$ and $x=$ $100 \mathrm{~m}$ at a depth of about $-100 \mathrm{~m}$, where the gradient also has a local maximum of $0.03 \mathrm{kPa} / \mathrm{m}$, compared with the surrounding average of $0.02 \mathrm{kPa} / \mathrm{m}$. Parallel to the interface the circular shape of the filled grey pore pressure gradient contours known from Fig. 7(c) is contracted. In block 2 the pore pressure gradient is steeper than in the corresponding part of the homogeneous half space model (Fig. 7(c)).

Generally in Fig. 7(f) tilt amplitudes exceed those in the homogeneous half space model (Fig. 7(c)) especially next to the interface. The spreading of the upper butterfly wing in Fig. 7(f) between $x=0 \mathrm{~m}$ and $x=100 \mathrm{~m}$ is considerably smaller compared with the situation in the homogeneous half space (Fig. 7(c)): between the well and the interface tilt changes to negative values - at the same distance from the well, where in the homogeneous model still positive values occur. The course of the tilt zero-line is less extended in this part of the model domain. Furthermore, a deflection of the tilt contour lines appears in Fig. 7(f) on the deeper butterfly-wings with negative values. The contour line of $-0.4 \mu \mathrm{rad}$ spreads out wider than in the homogeneous half space, whereas the contour line of $-0.7 \mu \mathrm{rad}$ spreads out less. Along the well's vertical axis tilt is not as in the homogeneous half space. Due to numerical limits in contour line plotting this feature is not clearly obvious in Fig. 7(c, f), but a closer inspection shows that in Fig. 7(f) at $x=0 \mathrm{~m}$ and $z=-30 \mathrm{~m}$ a local positive tilt maximum exists in between the zeroline. Below the well the tilt zero-line bends slightly towards the interface 
and is located at $x=10 \mathrm{~m}$ at the bottom of the model domain. In block 2 variations in tilt amplitudes are less pronounced than in block 1 and $\Delta \gamma_{x}$ is negative throughout; its value decreases from $-2.5 \mu \mathrm{rad}$ on top of the fault to $-0.2 \mu \mathrm{rad}$ at $x=300 \mathrm{~m}$, at the model bottom. Along the well's axis above and especially below the well's centre, the direction arrows of deformation show a slight deflection from the vertical. Below the well they have a component towards the interface.

\section{FIGURE 07}

Fig. 8 presents 2D slices which show horizontal field patterns in $\mathrm{x}-\mathrm{y}$ planes at four different shallow depths of both models of Fig. 7. The depths between $z=-5 m$ and $z=-10 m$ are typical installation depths for near surface tilt measurements [33, 32, 1, 34, 3]. The figure's left hand side (Fig. 8(a-d)) comprises slices of the homogeneous half space model of small-grained sand (compare Fig. 7(a-c)). The figure's right hand side (Fig. 8(e-h)) shows slices of the half space model with interface (compare Fig. $7(\mathrm{~d}-\mathrm{f})$ ). The contour lines delineate total tilt $\left(\Delta \gamma=\sqrt{\Delta \gamma_{x}^{2}+\Delta \gamma_{y}^{2}}\right)$. Except of some loops and undulations due to small amplitude variations in Fig.8(a-d) and a model resolution of some $10 \mathrm{~m}$, nearly circular contour lines, a circular grey scale pattern for the pore pressure gradient and arrows for the deformation direction pointing towards the well reflect the undisturbed subsoil. The $1.5 \mu \mathrm{rad}$ contour line in Fig. 8(a) and the $1.2 \mu \mathrm{rad}$ contour line in Fig. 8(b) each appear twice, so that strongest tilt must appear in between. In Fig. 8(d) the tilt zero-line cuts the $\mathrm{x}$-axis at $x=-60 \mathrm{~m}$ and $x=60 \mathrm{~m}$ and is also indicated by a reversal of the deformation direction arrows. 
In the model with material interface (Fig. 8(e-h)) an anomalous total tilt maximum of more than $2.5 \mu \mathrm{rad}$ appears next to the interface. Particularly close to the surface at $z=-5 m$ (Fig. $8(\mathrm{e}))$ this feature is outstanding. The contour line is lobe-shaped and has no circular symmetry with respect to the well's position. Moreover, the $1.5 \mu \mathrm{rad}$ contour line also shows some asymmetry in its course in block 1 of the model on the one hand and in block 2 on the other hand. An anomalous pattern caused by the interface is also visible in Fig. $8(\mathrm{e}-\mathrm{h})$ in the grey-scale pattern of the pore pressure gradient and in the deformation direction indicated by the arrows.

FIGURE 08

\subsection{Summary and interpretation of results}

The modelling results shown in Fig. 7 predict that if an interface exists in the subsoil, pump induced tilt and pore pressure fields - especially in the vicinity of the interface - will deviate strongly from those of a subsoil without an interface. The corresponding horizontal slices in Fig. 8 confirm the existence of strong and measurable anomalies, also close to the surface. Major deviations caused by the existence of an interface are (1) non-axisymmetric tilt and pore pressure fields with respect to the well's vertical axis, (2) steeper pore pressure gradients in block 1 , at the interface and in parts of block 2 near the interface, (3) intensification of the surface tilt maximum at the side of block 1 towards the interface, while (4) the horizontal position in the $\mathrm{x}$-coordinate of the tilt maximum at surface differs from the homogeneous half space case of $1 / \sqrt{2}$ times the well screen depth and (5) a tilt maximum is located directly next to the interface, (6) a tilt zero-line not encircling 
the well position and a significant change in its course, (7) a different tilt field pattern especially between well and interface, (8) change in tilt strike direction particularly below the well, where strike direction is shifted towards the interface.

Generally, next to a less permeable boundary, withdrawal of fluid will happen from a reduced catchment volume, if compared with a homogeneous half space. Well drawdown will be stronger and higher pore pressure gradients appear particularly in the reduced volume between well and boundary (i. e. the interface). Resulting high pore pressure gradients are likely to be the cause for strong pump induced tilt amplitudes. This effect should be even more intense in a layered half space, where horizontal aquicludes further reduce the catchment volume of the well, especially with a fault as a fluid barrier.

According to Lehmann [1] and Wang and Kümpel [17] in a homogeneous subsurface with a $100 \mathrm{~m}$ deep well the surface tilt maximum would appear within a radial distance of $70 \mathrm{~m}$ from the vertical well axis. However, in the model with an interface the surface maximum seems to focus to where the material interface crops out at the surface. To test this observation, models with the same geometry as before (Figs. 4 and 7 (f)), but different interface locations in x-position were calculated. Location and absolute amplitude of the tilt maxima at the surface, at the side closest to the interface are extracted and shown in Fig. 9. Amplitudes, i. e. the absolute values of tilt maxima for different interface distances lie within $2.4 \mu \mathrm{rad}$ and $4.3 \mu \mathrm{rad}$ - with the amplitude of the surface maximum of the homogeneous half space model as the lower limit. Hence, the existence of a material interface causes higher 
surface tilt maximum amplitudes. In Fig. 9 a trend of increasing amplitudes with decreasing well-interface distances is obvious, with the exception of the model with $20 \mathrm{~m}$ distance. This trend indicates that the closer the interface is to the well, the higher is the surface tilt maximum. However, if the interface is too close $(20 \mathrm{~m})$ the higher rigidity of the subsurface material beyond the interface (in block 2) causes smaller amplitudes. The surface maximum of the homogeneous half space solution is located $73 \mathrm{~m}$ away from the vertical well axis and thus fulfils the rule to be at $1 / \sqrt{2}$ times the well depth within the resolution of the FE mesh at the surface. Regarding the positions of tilt surface maxima in models with interface, the maxima tend to follow the interface. At well interface distances of $20 \mathrm{~m}$ and $40 \mathrm{~m}$, the maximum locates right at the interface (within the spatial resolution limited by discretisation). At larger distances from the well, i. e. $60 \mathrm{~m}, 80 \mathrm{~m}$ and $125 \mathrm{~m}$, the maximum appears at the interface, but for $150 \mathrm{~m}$ and $175 \mathrm{~m}$ distance the maximum locates close to the maximum calculated for the homogeneous half space and the amplitude is only slightly stronger. Most likely due to the large distance of the interface from the well, the influence of the interface on the tilt field is too small to significantly bias the tilt field. The tilt field thus looks more like that of the homogeneous half space. Accordingly, at well-to-fault distances larger than $150 \mathrm{~m}$ the tilt maximum approximates the one of the homogeneous half space. Amplitudes in a setting with a fault always exceed those of a homogeneous one. This is due to a reduced catchment volume bounded by a less permeable material which causes stronger pore pressure gradients.

FIGURE 09 
444

A similar approach as before was applied to investigate the dependency of the position of the surface tilt maximum on the depth of the well. The well is at $x=0 \mathrm{~m}$ and the interface is kept fixed at $x=70 \mathrm{~m}$ horizontal distance from the well. This position of the interface is exactly where the surface tilt maximum would appear in a homogeneous half space for a well depth of $z=-100 \mathrm{~m}$. However, in a sequence of models the well depth is subsequently changed from $-20 \mathrm{~m}$ to $-175 \mathrm{~m}$. Fig. 10 shows locations and amplitudes of the total tilt maxima at the surface, at the side closest to the interface. Amplitudes at the surface decrease as the well depth increases. With increasing well depth the tilt maximum at the surface moves towards the interface, but if the well is at a depth of $-100 \mathrm{~m}$ and deeper, tilt maxima at the surface seem to locate at about $5 \mathrm{~m}$ in front of the interface, but do not appear beyond it for larger well depths. For a comparison Fig. 10 also shows the position of tilt maxima in a homogeneous half space. For instance, for a well depth of $-60 \mathrm{~m}$ the maximum is shifted towards the interface and occurs at $x=60 \mathrm{~m}$, whereas for a homogeneous half space this maximum would appear at $x=42 \mathrm{~m}$. Positions of surface maxima for a half space with interface and homogeneous half spaces nearly agree for well depths of $-80 \mathrm{~m}$ and $-100 \mathrm{~m}$, but if the well is deeper the interface seems to act as a barrier for the appearance of the surface tilt maxima.

FIGURE 10 


\section{Layered half space}

A more realistic representation of a sedimentary subsoil with fault might be a layered half space cut by a fault zone of finite length as shown in Fig. 2 . In section 5.1 the results for the model shown in Fig. 2(b) are described and compared to those of a layered subsoil without a fault (Fig. 2(a)). The poroelastic properties within the fault are those of loam, which is less permeable then small-grained sand and higher permeable than clay (compare Tab. 1). In the upper part of the fault zone, where no mixing is assumed, poroelastic parameters are those of small-grained sand. In section 5.2 the results for Fig. 2(c) are presented. Instead of a mixed materials fault zone, the four layers of the formation in block 1 are offset downwards by two $25 \mathrm{~m}$ steps. All results are described in the same manner as in section 4 . The well lies in block 1 within the confined aquifer (layer 3). Block 2 comprises the model region on the other side of the fault.

\subsection{Fault zone of mixed material}

With the same representation as in Fig. 7, Fig. 11(a-c) shows the modelling results of the COMSOL calculations for an x-z cross-section at $y=0 \mathrm{~m}$ for the undisturbed layered subsoil (Fig.2(a)). Fig. 11(a) depicts surface tilt at $z=0 m$ which is symmetric with respect to $x=0 m$ (well-axis) where tilt is zero. The maximum locates at $x=-140 \mathrm{~m}$ and $x=140 \mathrm{~m}$ with an amplitude of $-7.1 \mu \mathrm{rad}$. This agrees with observations from Fabian [3] who investigated the effect of a layered subsoil. He found that a layered subsurface causes the surface tilt maximum to occur at the same or at a larger distance than expected for a homogeneous subsurface. The pore pressure gradient at 
the surface is also symmetric to a maximum of $3 \cdot 10^{-5} \mathrm{kPa} / \mathrm{m}$ at $x=0 \mathrm{~m}$.

In Fig. 11(c) grey-shaded filled contours represent the pore pressure gradient, contour lines show tilt in the x-direction $\left(\Delta \gamma_{x}\right)$ and vectors show the direction of deformation. The pore pressure gradient is strongest at the well screen $(50 \mathrm{kPa} / \mathrm{m})$ and decreases radially within the pumped layer. Although amplitudes vary within the distinct layers a decrease in the pore pressure gradient occurs with increasing horizontal distance to the well's vertical axis. The strongest pore pressure gradients appear, along with the strongest tilt values, at layer boundaries. In the pumped aquifer (layer 3, compare Fig. 2) a butterfly-shaped tilt contour line structure is similar to that of a homogeneous half space (Fig. 7(c)), but with sharp corners at the upper and lower layer boundaries and a local maximum in the lower aquiclude (x: $-700 \mathrm{~m}$ to $-250 \mathrm{~m}$ and $250 \mathrm{~m}$ to $700 \mathrm{~m}$, z: $-120 \mathrm{~m}$ to $-175 \mathrm{~m})$. The white tilt zeroline coincides with the vertical well axis. Between the well and the upper aquiclude (layer 2) this line has a convex-shaped form bounded by the horizontal layer interface. The tilt zero-line does not appear shallower than $-45 \mathrm{~m}$, in contrast to about $-25 \mathrm{~m}$ depth as in the homogeneous half space (Fig. 7(c)). At $x=0 m$ (well-axis) all deformation vectors point vertically downwards. The vectors to the left and to the right are symmetrically deflected with respect to the well axis. Generally, all tilt and pore pressure gradient patterns show this type of cylinder symmetry. Slices of the fields in $\mathrm{x}-\mathrm{y}$ planes at different depths are not shown, as they show a typical radially symmetric pattern similar as for the homogeneous half space (Fig. 8(a-d)).

Fig. 11(d-f) shows pump induced tilt, pore pressure gradient and deformation for a layered subsoil cut by a fault zone. As before, surface tilt and 
pore pressure gradients on the symmetry plane $(y=0 m)$ are presented in the top panels (Fig. 11(d, e)). Tilt has strong and sharp anomalies. A pronounced minimum of $-40.5 \mu \mathrm{rad}$ is located at $x=110 \mathrm{~m}$ on top of the fault zone. A surface tilt peak of $+12.1 \mu \mathrm{rad}$ occurs at $x=0 \mathrm{~m}$ on top of the well. This positive tilt maximum causes two locations of zero-tilt at the surface, at $x=-70 \mathrm{~m}$ and in between $x=0 \mathrm{~m}$ and $x=5 \mathrm{~m}$, where a strong gradient prevails. The pore pressure gradient along the surface is not symmetric either. The maximum does not locate at $x=0 \mathrm{~m}$ as in Fig. 11(b). Instead, it appears just behind the fault at $x=130 \mathrm{~m}$ with a more than 10 times higher amplitude compared to a setting without a fault.

In Fig. 11(f) the pore pressure gradient has large values in layer 2 and within the fault zone because both these structures act as barriers. Amplitudes are larger in block 1 than in block2. A local minimum as low as $0.01 \mathrm{kPa} / \mathrm{m}$ appears along the fault zone's margin to block 1 in the confined aquifer (layer 3). Within the fault zone the pore pressure gradient varies from $0.01 \mathrm{kPa} / \mathrm{m}$ to $1 \mathrm{kPa} / \mathrm{m}$ over the fault's width of $20 \mathrm{~m}$. At larger depths (Fig. 11(f)) local tilt maxima occur at layer boundaries and especially in corners formed by layer interfaces, where strong tilt gradients are induced. The butterfly-like tilt pattern as in Figs. 7(c) and 11(c) are hardly recognisable. The tilt zero-line encircles small areas, e.g. at the upper right corner of the confined aquifer in block 1 , at $x=100 \mathrm{~m}$ and $z=-75 \mathrm{~m}$. At $x=-5 \mathrm{~m}$ the tilt zero-line roughly follows the vertical from layer 2 to the bottom of the model area with an excursion below the well and layer 4. Aside, the tilt zero-line describes a curvy course from top to bottom at the left side of the well and intersects layer 2 at about $x=-100 \mathrm{~m}$. Within the fault 
zone tilt amplitudes vary vertically from $-40.5 \mu \mathrm{rad}$ at the top down to a minimum value of $1.0 \mu \mathrm{rad}$ at $z=-75 \mathrm{~m}$ and then increase again to a local maximum of $-21 \mu \mathrm{rad}$ at $z=-150 \mathrm{~m}$. A local tilt anomaly slightly higher than $-3.0 \mu \mathrm{rad}$ is visible at $x=-820 \mathrm{~m}$ at a depth of $z=-135 \mathrm{~m}$. Tilt amplitudes in block 2 range between $-1 \mu \mathrm{rad}$ and $-35 \mu \mathrm{rad}$ and appear strongest close to the fault, whereas in block 1 they range between $10 \mu \mathrm{rad}$ and $-38 \mu \mathrm{rad}$ and spread throughout the complete model block. Deformation is purely vertical along a diagonal line from the surface at $x=-500 \mathrm{~m}$ down to the bottom at $x=-620 \mathrm{~m}$. Near the well and the fault, deformation direction vectors have a strong $\mathrm{x}$-component which points towards this diagonal line.

\section{FIGURE 11}

Fig. 12(a-d) shows four slices with pump induced tilt, pore pressure gradient and deformation fields for the model with four layers and a $20 \mathrm{~m}$ wide fault zone with the same representation as before (Fig. 8). All depth slices locate above the fault mixing zone and except for block 1 in $(d)$, within the upper aquifer. As for the model with a single interface (Fig. 8(e-h)) field patterns deviate from the cylinder symmetry of the homogeneous half space case and the layered half space. Anomalies are remarkable: The pore pressure gradient is zero in the upper $10 \mathrm{~m}$ to the left of the well $(x<0 \mathrm{~m})$ and at $x>300 \mathrm{~m}$. At $z=-20 \mathrm{~m}$ values increase in block 1 . At $-35 \mathrm{~m}$ depth the pore pressure gradient is significantly increased in block 1 of the model. At this depth lies the upper aquiclude (layer 2). Strong anomalies in tilt contour lines as well as in the pore pressure gradient field appear close to 
the fault zone. In Figs. $12(\mathrm{a}, \mathrm{b})$ the $4.5 \mu \mathrm{rad}$ total tilt contour line appears twice in block 1 . The nearby $5.1 \mu \mathrm{rad}$ contour indicates a tilt maximum in between, corresponding with Fig. 11(f). On the other hand, in Fig. 12 (a, b) the total tilt contour lines of 1.8, 3.7 and 4.5 $\mathrm{rad}$ are closed loops in block 1 and encircle a local tilt maximum at about $x=-80 \mathrm{~m}$. Also remarkable is the direction of deformation at the different depths. A fictitious point of attraction for the deformation direction arrows is at the x-axis. The point changes its location along the x-axis: near the surface it locates at approximately $x=-70 \mathrm{~m}$, at $z=-20 \mathrm{~m}$ it can be found at $x=-100 \mathrm{~m}$ and at $z=-35 m$ at $x=-90 m$.

\section{FIGURE 12}

Modelling results shown in Fig. 11 and 12 reveal strong anomalies in tilt, pore pressure gradient and deformation fields in a layered subsoil with a fault zone (Fig. 11(d-f)) with respect to a layered subsoil without a fault (Fig. 11(a-c)). Therefore, a fault in a layered subsoil can cause (1) a complete disturbance of the symmetry with respect to the vertical well axis in pore pressure gradient, tilt and deformation fields, (2) a strong tilt surface maximum at the outcrop of the fault, (3) two locations of zero-tilt at surface, (4) local tilt maxima with steep tilt gradients located preferably at edges and corners of layers, (5) an isolated tilt maximum at a larger distance from well and (6) vertical deformation (a subsidence trough) not above the well.

\subsection{Step fracture}

In contrast to the foregoing models, a four-layer subsoil with a step fracture is presented (Fig. 2(c)). The results of this model are illustrated in the 
same manner as the previous models.

Surface tilt in the the x-direction (Fig. 13(a)) is not symmetric with respect to the well. A pronounced negative tilt maximum of $-5.4 \mu \mathrm{rad}$ and a less prominent one of $-2.5 \mu \mathrm{rad}$ exist at $x=110 \mathrm{~m}$ and $x=-150 \mathrm{~m}$, respectively. In between, a positive maximum of $0.4 \mu \mathrm{rad}$ causes zero-tilt to occur at $x=-12 m$ and $x=0 \mathrm{~m}$. At distances of $900 \mathrm{~m}$ from the well's axis, surface tilt levels just below $-1 \mu \mathrm{rad}$ at both sides. The surface pore pressure gradient has two maxima; $1.2 \cdot 10^{-5} \mathrm{kPa} / \mathrm{m}$ at $x=0 \mathrm{~m}$ and $1.6 \cdot 10^{-5} \mathrm{kPa} / \mathrm{m}$ at $x=125 \mathrm{~m}$, with a minimum of $1.1 \cdot 10^{-5} \mathrm{kPa} / \mathrm{m}$ in between. The gradient decreases monotonically with increasing distance from the well. The vertical slice in the $\mathrm{x}-\mathrm{z}$ plane is shown in Fig. 13(c). Pore pressure gradient amplitudes change significantly in the different layers of block 1 , block 2 and within the stepped fault. Here, the pore pressure gradient variations range between $0.001 \mathrm{kPa} / \mathrm{m}$ and $0.1 \mathrm{kPa} / \mathrm{m}$. At the well screen the pore pressure gradient reaches $22 \mathrm{kPa} / \mathrm{m}$. As described for the surface tilt, the tilt field in the subsurface is not symmetric either. Gradients of tilt are high, including sign changes at corners where different materials locate next to each other, e.g. inside the fault zone at depths of $z=-50 \mathrm{~m}$ and $z=-75 \mathrm{~m}$. The tilt zero-line follows the vertical well axis from the well to the surface. A butterfly-pattern is not clearly obvious. Nevertheless, strongly deformed upper wings encircled by the white zero-tilt line are imaginable. The right wing is contracted and much smaller than in a subsoil without a fault (Fig. 11(c)) whereas the left wing is wider and extends up to the surface. Purely vertical deformation occurs along a vertical line at about $x=-30 \mathrm{~m}$. All other vectors have a small $\mathrm{x}$-component towards this line, which becomes less strong 
as the distance increases.

\section{FIGURE 13}

Fig. 14 shows four horizontal slices of the model of a layered soil cut by a step fracture. Illustrations are identical to those of Figs. 8 and 12 . The pore pressure gradient, tilt and deformation field in the upper aquifer (layer 1) is shown in the upper three panels (Fig. 14(a-c)), in block 1 in Fig. 14(d) and in the fault zone. Pore pressure gradients are extremely small, with maximum values as low as $0.001 \mathrm{kPa} / \mathrm{m}$. The area of block 1 in Fig. 14(d) shows a part of layer 2 (clay) that overlies the well. Here, pore pressure gradient amplitudes are significantly higher reaching a maximum of $0.25 \mathrm{kPa} / \mathrm{m}$ at the well's vertical axis. Within the fault from $x=100 \mathrm{~m}$ to $x=120 \mathrm{~m}$ the gradient decreases rapidly. Contour lines of total tilt encircle a fictitious centre which locates at about $x=-10 \mathrm{~m}$, i. e. $10 \mathrm{~m}$ away from the well's centre. In Fig. 14(a) the total tilt contour lines of 1.8 and $2.3 \mu \mathrm{rad}$ appear twice. Therefore, a tilt maximum must be in between these lines, namely at $y=0 \mathrm{~m}$ and $x=-180 \mathrm{~m}$. This maximum corresponds with the representation of Fig. 13(a). The fault adds a strong anomaly to the tilt contour line pattern. Beyond the fault in block 2 tilt amplitudes decrease rapidly with horizontal distance to the fault as well as with increasing depth and they show smaller amplitudes than in block 1 . Tilt amplitudes also decrease from the tilt maximum in block 1 (at the surface at $x=-180 \mathrm{~m}, y=0 \mathrm{~m}$ ) towards the model's left side. All shown deformation vectors point towards a point near the well's axis at about $x=-10 m, y=0 m$.

FIGURE 14 
The pump induced fields of a layered model with a step fracture-type zone (Figs. 13 and 14) are anomalous with respect to those of a model without a fault (Fig. 11(a, b)). Anomalies include (1) a disturbance of the symmetry with respect to the vertical well axis in pore pressure gradient, tilt and deformation fields, (2) tilt surface maximum increase at the fault, (3) two locations of zero-tilt at surface and (4) local tilt maxima with steep tilt gradients located preferably at edges and corners of layers. These anomalies are similar to those reported for the model of a layered subsurface cut by a fault zone filled partially with loam (Fig. 11). Overall, amplitudes of tilt and pore pressure gradients in this model (layered half space with step fracture) are slightly smaller than those of the model without a fault (compare Figs. 13(a-c) and 11(a-c)). They are significantly smaller than amplitudes in a model with uniform fault zone of loam (compare Figs. 13(d-f) and 11(d-f)). In contrast to a fault zone of loam, a step fault zone provides pathways for fluids in its segments of higher permeability. High pore pressure gradients are unlikely to build up because the pumped aquifer is only partially bounded by the fault. Tilt amplitudes are consequently less strong. A fault of good conductivity could even cause groundwater to flow from the upper free aquifer in block 2 through a pathway in the fault zone into the confined aquifer in block 1 to partially by-pass confinement and feed the well.

\section{Discussion}

As calculated for example by Fabian [3] the course of the tilt zero-line within a subsoil is influenced in a consistent way, if layers are present. The 
tilt maximum at surface is horizontally shifted to larger distances compared to the homogeneous half space. At the surface the direction of deformation and zero-tilt are as for the homogeneous half space. Horizontal layers do not disturb cylinder symmetry of pump induced fields with respect to the well axis, but those layers bias the field pattern laterally. Our results from modelling homogeneous and horizontally layered half spaces (Figs. 7(a-c) and 11(a-c)) confirm those earlier modelling results.

Anomalous tilt signals in various sedimentary basins in Germany were measured by Fabian and Kümpel [34]. The authors found that the tilt strike direction does not agree with the direction towards the well. Furthermore, they noticed a surface distribution of tilt amplitudes different to what they expected from typical tilt fields of a homogeneous or layered subsurface. Based on the before shown numerical models it is obvious that a fault in the vicinity of a pumping well disturbs the symmetry of deformation, tilt and pore pressure fields with respect to the vertical well axis. Accordingly, a fault in subsoil is very likely to attribute to anomalies in pump induced fields at the surface.

The models of this study which deal with a fault that acts as a barrier to fluid flow show that strong anomalies in pump induced tilt, pore pressure gradient and deformation can occur. Nevertheless, depending on the particular geological regime, faults can also provide pathways for fluid flow $[36,27]$. Fluids from aquifers at the opposite side of the fault and possibly from aquifers above or below the pumped aquifer can flow within the fault towards the well. In such a scenario pump induced pore pressure gradients become small and comparatively low tilt amplitudes occur. The modelling 
results for a fault with step fractures as shown in Fig. 13 confirm that pump induced anomalies especially at the surface are not that strong, if the fault acts only partially as a fluid barrier. On the other hand, if a tilt survey reveals very strong anomalies, this can be interpreted as a fault acting as an efficient barrier, whereas a weak anomaly located on top of a fault might document pathways in the subsoil.

All interpretations are based on models that include a number of simplifications and assumptions. By applying the theory of linear poroelasticity it is assumed that variations in physical parameters are so small that linear system behaviour is a good approximation to reality. However, many geologic processes show significant parameter changes and are inelastic, e.g. clays tend to display non-recoverable behaviour [37]. Other non-linear influences of deformation on the poroelastic parameters are chemical reactions or the closing of pore spaces. Wilson and Gorelick [38] suggested that inelastic properties are predominantly enhanced by cyclical pumping, which is not simulated here. Also, the soil is assumed to be fully water saturated. Tseng et al. [39] showed that neglecting groundwater drawdown as it occurs in partly saturated soils, can lead to an underestimation of soil displacement. Models in this study do not account for soil consolidation which may result in a porosity decrease. Neither do they consider the fact that the water originally contained inside the well is pumped out first before pumping from the aquifer starts nor that the water level depression near the well is considered. Characteristics of a fault zone are also probably more complex than assumed here. For instance, the shear modulus, G, is probably lower than in the undisturbed subsurface as a fault zone represents a zone of weakness. 
Topography is neglected in our modelling, however, a topographic change represents at least additional loading, can cause compaction, and therefore alter poroelastic parameters. These limitations may be significant if detailed investigations of a specific model unit or feature have to be made. However, effects of assumptions and simplifications made here are assumed to be of minor significance for the general tilt and pore pressure fields. As this work focuses on the general pattern of deformation in the subsoil this conceptualization of a soil system is probably adequate. Because modelling in this study is limited to steady-state cases, further investigations should deal with the time dependency of signal build-up.

\section{Conclusion}

Based on numerical models it has been shown that a fault in a sedimentary subsoil can have a significant influence on the deformation field in the surface. For an interpretation of tilt data, faults or similar geological structures have to be considered as they produce anomalies and thus bias the interpretation. Amplitude changes due to these anomalies are of a few $\mu \mathrm{rad}$ or even stronger and can be resolved by high-resolution tiltmeters. The location of the tilt maximum at the surface, its amplitude and the course of the tilt zero-line are also the subject of disturbance caused by subsurface interfaces or faults. The surface tilt maximum preferentially locates on top of the fault zone and achieves comparatively strong amplitudes if the fault zone acts as a barrier to fluid flow. The strength of an observed tilt anomaly in pumping test experiments can thus indicate whether a fault acts as a barrier or a pathway, assuming that tiltmeters are installed at adequate positions. These facts 
are vital for tilt surveys especially with a limited number of instruments. Simplified 3D poroelastic models can reliably predict anomalies in a wellknown geological setting and thus provide the possibility to identify suitable tiltmeter positions in advance to field studies.

\section{Acknowledgement}

We thank Professor Heiner Villinger, Universität Bremen, for supporting this study and providing computing facilities. We are also grateful to an anonymous reviewer for valuable comments and suggestions which vastly improved the strength and quality of this paper.

\section{References}

[1] K. Lehmann, Porendruckinduzierte Neigungssignale in geringen Tiefen und ihre Modellierung im homogenen Halbraum, Berichte aus der Geowissenschaft, Shaker Verlag, Aachen, 2001. Doctoral thesis, Rheinische Friedrich-Wilhelms-Universität Bonn, download from: http://www.shaker-online.com/.

[2] D. W. Vasco, K. Karasaki, O. Nakagome, Monitoring reservoir production using surface deformation at the Hijiori test site and the Okuaizu geothermal field, Japan, Geothermics 31 (2002) 303-342.

[3] M. Fabian, Near surface tilt and pore pressure changes induced by pumping in multi-layered poroelastic half-spaces, number 229 in Berichte aus dem Fachbereich Geowissenschaften, ISSN: 
0931-0800, Universität Bremen, 2004. Doctoral thesis, Rheinische Friedrich-Wilhelms-Universität Bonn, URN: http://nbnresolving.de/urn:nbn:de:hbz:5-03724,URL: http://hss.ulb.unibonn.de/diss_online/math_nat_fak/2004/fabian_marcus.

[4] H.-C. Chen, Pump induced tilt and pore pressure variations at Fuhrberg, north of Hanover and their modeling in layered half space, 2008. Doctoral thesis, Gottfried Wilhelm Leibniz Universität Hannover, download from http://www.liaghannover.de/fileadmin/produkte/20090616173956.pdf.

[5] M. Tolstoy, S. Constable, J. Orcutt, H. Staudigel, F. Wyatt, G. Anderson, Short and long baseline tiltmeter measurements on Axial Seamount, Juan de Fuca Ridge, Physics of the Earth and Planetary Interiors 108 (1998) 129-141.

[6] M. Fabian, H. Villinger, Long-term tilt and acceleration data from the Logatchev Hydrothermal Vent Field, Mid-Atlantic Ridge, measured by the Bremen Ocean Bottom Tiltmeter, Geochemistry, Geophysics, Geosystems 9 (2008).

[7] D. Castillo, S. Hunter, P. Harben, C. Wright, R. Conant, E. Davis, Deep hydraulic fracture imaging: recent advances in tiltmeter technologies, International Journal of Rock Mechanics and Mining Sciences 34 (1997) 47.e1-47.e9.

[8] E. Davis, C. Wright, S. Demetrius, J. Choi, G. Craley, Precise tiltmeter 
subsidence monitoring enhances reservoir management, in: SPE/AAPG Western Regional Meeting.

[9] J. Du, S. Brissenden, P. McGillivray, S. Bourne, P. Hofstra, E. Davis, W. Roadarmel, S. Wolhart, C. Wright, Mapping fluid flow in a reservoir using tiltmeter-based surface-deformation measurements, in: SPE Annual Technical Conference and Exhibition.

[10] G. Jentzsch, S. Koss, Interpretation of long-period tilt records at Blå Sjø, Southern Norway, with respect to variations in the lake level, Physics and Chemistry of the Earth 22 (1997) 25-31.

[11] A. Weise, G. Jentzsch, A. Kiviniemi, J. Kääriäinen, Comparison of long-period tilt measurements: results from the two clinometric stations Metsähovi and Lohja, Finland, Journal of Geodynamics 27 (1999) 237257.

[12] T. Jahr, H. Letz, G. Jentzsch, Monitoring fluid induced deformation on the earth's crust: A large scale experiment at the KTB location/Germany, Journal of Geodynamics 41 (2006) 190-197.

[13] A. Gebauer, T. Jahr, G. Jentzsch, Recording and interpretation/analysis of tilt signals with five ASKANIA borehole tiltmeters at the KTB, Review of scientific instruments 78 (2007).

[14] E. Davis, D. Astakhov, C. Wright, Precise deformation monitoring by high resolution tiltmeters, Geophysical Exploration 54 (2001) 425-432.

[15] V. Bense, E. V. den Berg, R. V. Balen, Deformation mechanisms and hydraulic properties of fault zones in unconsolidated sediments; the Roer 
Valley Rift System, The Netherlands, Hydrogeology Journal 11 (2003) 319-332.

[16] T. Jahr, G. Jentzsch, A. Gebauer, T. Lau, Deformation, seismicity, and fluids: Results of the 2004/2005 water injection experiment at the KTB/Germany, Journal of Geophysical Research 113 (2008).

[17] R. Wang, H.-J. Kümpel, Poroelasticity: Efficient modeling of strongly coupled, slow deformation processes in a multilayered half-space, Geophysics 68 (2003) 705-717.

[18] T. Jahr, G. Jentzsch, H. Letz, M. Sauter, Fluid injection and surface deformation at the KTB location: modelling of expected tilt effects, Geofluids 5 (2005) 20-27.

[19] J.-H. Kihm, J.-M. Kim, S.-H. Song, G.-S. Lee, Three-dimensional numerical simulation of fully coupled groundwater flow and land deformation due to groundwater pumping in an unsaturated fluvial aquifer system, Journal of Hydrology 335 (2007) 1-14.

[20] M. A. Biot, General theory of three-dimensional consolidation, Journal of Applied Physics 12 (1941) 155-164.

[21] J. Campbell, H.-J. Kümpel, M. Fabian, D. Fischer, B. Görres, C. J. Keysers, K. Lehmann, Recent movement patterns of the Lower Rhine Embayment from tilt, gravity and GPS data, Netherlands Journal of Geosciences / Geologie en Mijnbouw 81 (2002) 223-230. 
[22] A. Schäfer, T. Utescher, M. Klett, M. Valdivia-Manchego, The Cenozoic Lower Rhine Basin rifting, sedimentation, and cyclic stratigraphy, International Journal of Earth Sciences 94 (2005) 621-639.

[23] COMSOL, COMSOL Mutiphysics Modelling Guide (Version 3.2), COMSOL AB GmbH, 2005.

[24] AGI, User's manual no. B-91-1004, model 722 borehole tiltmeter, Applied Geomechanics Inc., Santa Cruz, CA 95062 (USA), 1991.

[25] J. Klostermann, J. Kremers, R. Röder, Rezente tektonische Bewegungen in der Niederrheinischen Bucht, Fortschritte in der Geologie von Rheinland und Westfalen 37 (1998) 557-571.

[26] K. Lehmann, J. Klostermann, R. Pelzing, Paleoseismological investigations at the Rurrand Fault, Lower Rhine Embayment, Netherlands Journal of Geosciences / Geologie en Mijnbouw 80 (2006) 139-154.

[27] G. Rawling, L. Goodwin, J. Wilson, Internal architecture, permeability structure, and hydrologic significance of contrasting fault-zone types, Geology 29 (2001) 43-46.

[28] M. Heynekamp, L. Goodwin, P. Mozley, W. Haneberg, Controls on fault-zone architecture in poorly lithified sediments, Rio Grande rift, New Mexico: Implications for fault-zone permeability and fluid flow, in: W. Haneberg, P. Mozley, J. C. Moore, L. Goodwin (Eds.), Faults and subsurface fluid flow in the shallow crust, volume 113 of American Geophysical Union Monograph, American Geophysical Union, 1999, pp. $27-49$. 
[29] H.-J. Kümpel, Poroelasticity: parameters reviewed, Geophysical Journal International 105 (1991) 783-799.

[30] H. F. Wang, Theory of linear poroelasticity with application to geomechanics and hydrogeology, Princeton University Press, Princeton, 2000.

[31] B. Hölting, Hydrogeologie, Enke-Verlag, Stuttgart, 5th edition, 1996.

[32] H. Kümpel, K. Lehmann, M. Fabian, G. Mentes, Point stability at shallow depths: experience from tilt measurements in the Lower Rhine Embayment, Germany, and implications for high-resolution GPS and gravity recordings, Geophysical Journal International 146 (2001) 699713.

[33] H. Kümpel, P. Varga, K. Lehmann, G. Mentes, Ground tilt induced by pumping: Preliminary results from the Nagycenk test site, Hungary, Acta Geodaetica et Geophysica Hungary 31 (1996) 6778.

[34] M. Fabian, H. Kümpel, Poroelasticity: observations of anomalous near surface tilt induced by ground water pumping, Journal of Hydrology 281 (2003) 191-209.

[35] K.-J. Bathe, Finite-Elemente-Methoden, Springer-Verlag Berlin, 2nd edition, 2002.

[36] R. J. Knipe, Diagenesis and basin development, volume 36, AAPG Studies in Geology, pp. 135-148.

[37] J. Poland, Land subsidence in the western states due to ground-water overdraft, Water Resources Bulletin 8 (1972) 118-131. 
${ }_{871}[38]$ A. Wilson, S. Gorelick, The effects of pulsed pumping on land subsidence 872 in the Santa Clara Valley, California, Journal of Hydrology 174 (1996) $873 \quad 375-396$.

${ }_{874}$ [39] C.-M. Tseng, T.-L. Tsai, L.-H. Huang, Effects of body force on transient 875 poroelastic consolidation due to groundwater pumping, Environmental $876 \quad$ Geology 54 (2008) 1507-1516. 


\section{FIGURES}

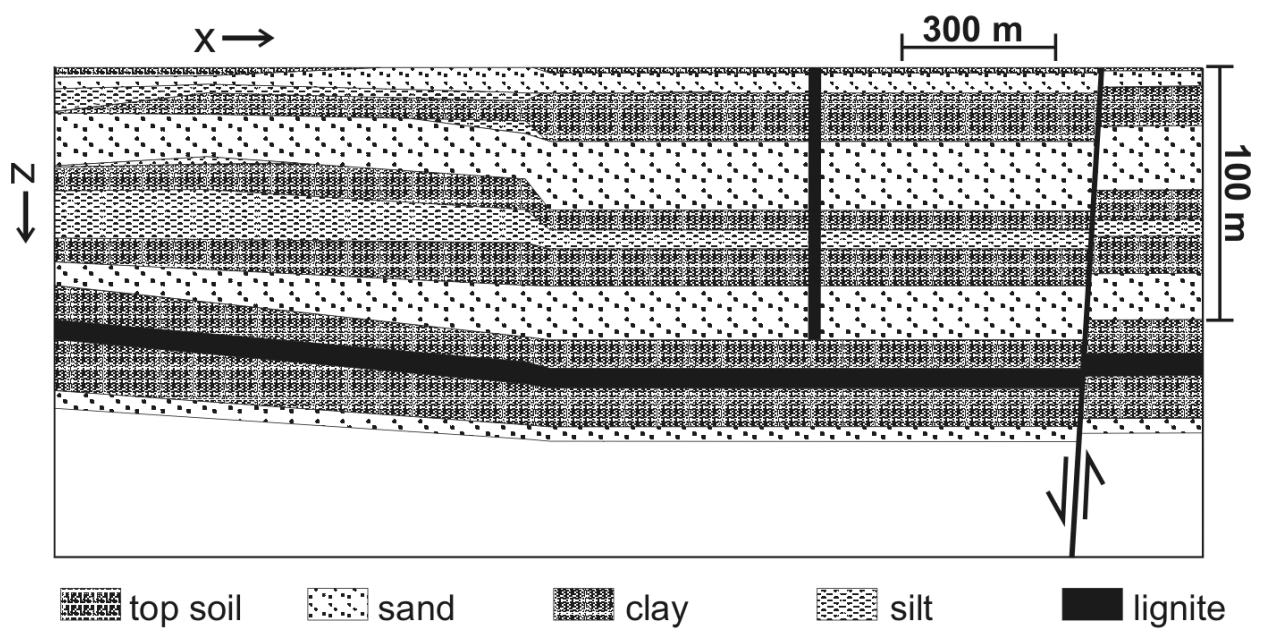

Figure 1: Typical geological cross section from the Lower-Rhine Embayment simplified and redrawn after Fabian [3]. At the top of a bedrock (white) a some hundred meter thick stack of unconsolidated fully saturated sediments with alternating layers of aquifers (sand) and aquicludes (clay, silt, lignite) bears groundwater. The black vertical line shows a possible position of a well tapping those aquifers, whereas the angled line on the right depicts a tectonic fault which offsets the layers. 

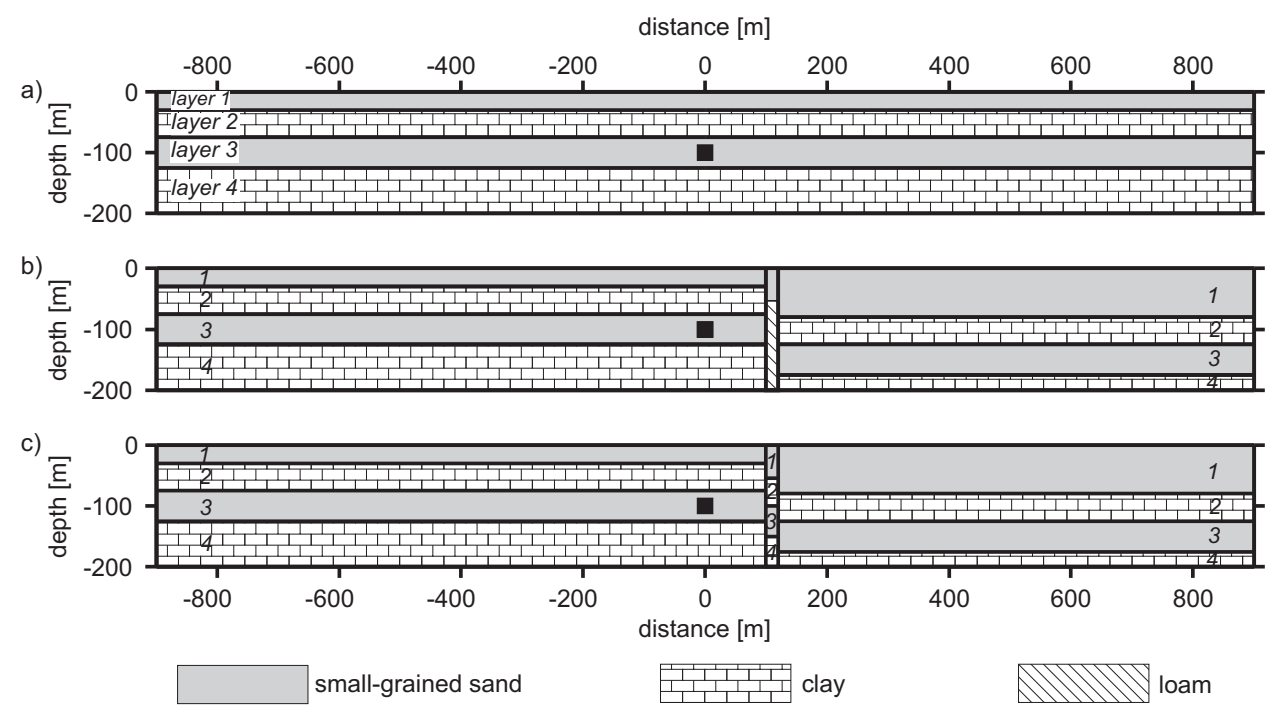

Figure 2: Sketch of models with layers. In Tab. 2 they are referred to as "undisturbed" (a), "fault zone" (b) and "step fracture" (c). The well is marked by a black rectangle. Layers are numbered 1-4. Poroelastic parameters are given in Tab. 1. 


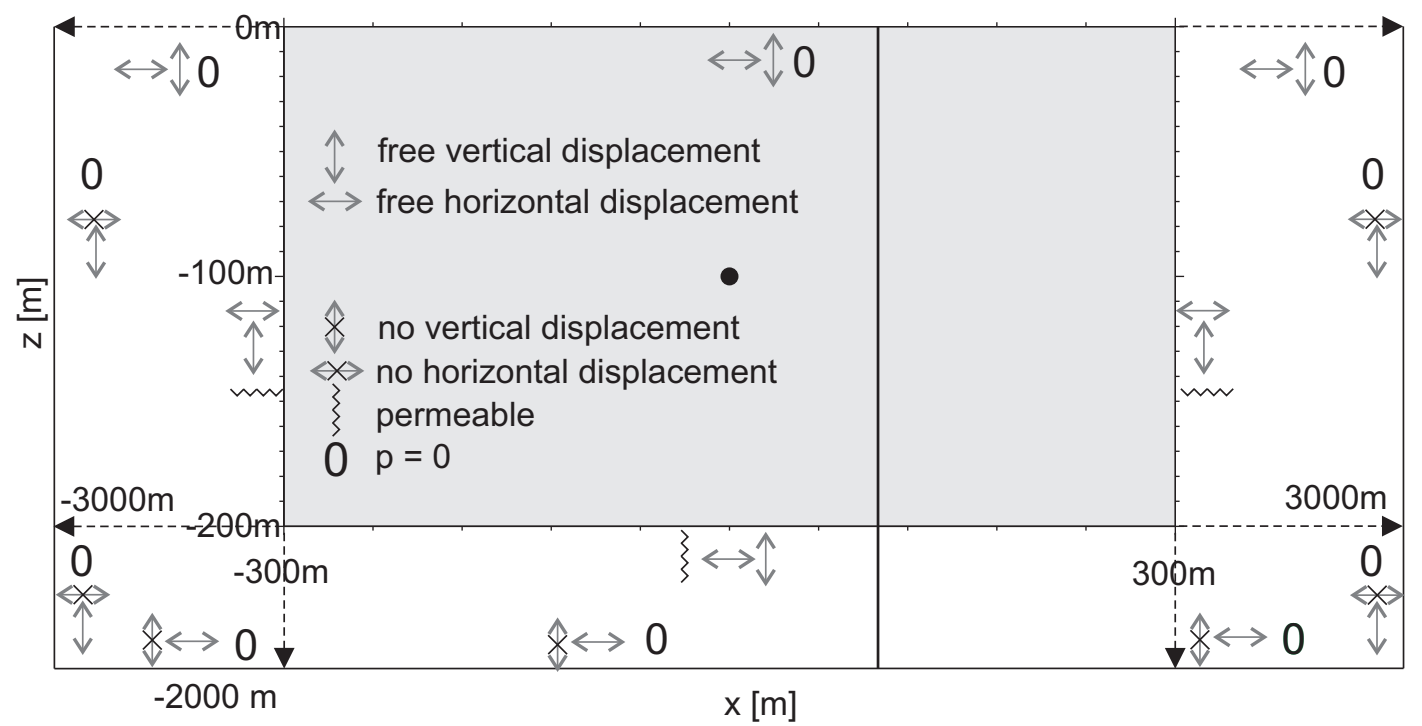

Figure 3: Boundary conditions depicted not true to scale as a $2 \mathrm{D}$ sketch in the symmetry plane $(x-z$ plane at $y=0 \mathrm{~m})$. The grey shaded area extending from $-300 \mathrm{~m}$ to $300 \mathrm{~m}$ in $x$ and $0 m$ to $-200 m$ in $z$ depicts the model domain. The not shown extension in $y$ is from $0 \mathrm{~m}$ to $150 \mathrm{~m}$. This model part is embedded into a ten times larger block of the same material composition extending from $-3000 \mathrm{~m}$ to $3000 \mathrm{~m}$ in $x, 0 \mathrm{~m}$ to $-2000 \mathrm{~m}$ in $z$ and $0 m$ to $1500 m$ in $y$. The contact surfaces between inner (grey) and outer part (white) can move freely and groundwater can pass without resistance. At the outer boundaries of the large model block (white) the surfaces perpendicular to $x$ are fixed against motion in $x$, the surfaces perpendicular to $y$ are fixed against motion in $y$ and the bottom cannot move vertically. At those surfaces (excess) pore pressure vanishes. The free surface where pore pressure also vanishes is common for the complete model domain. The symmetry plane at $y=0 m$ cannot move in the $y$-direction and is impermeable to normal flux. The black circle marks the well position and the black vertical line depicts the material interface. 


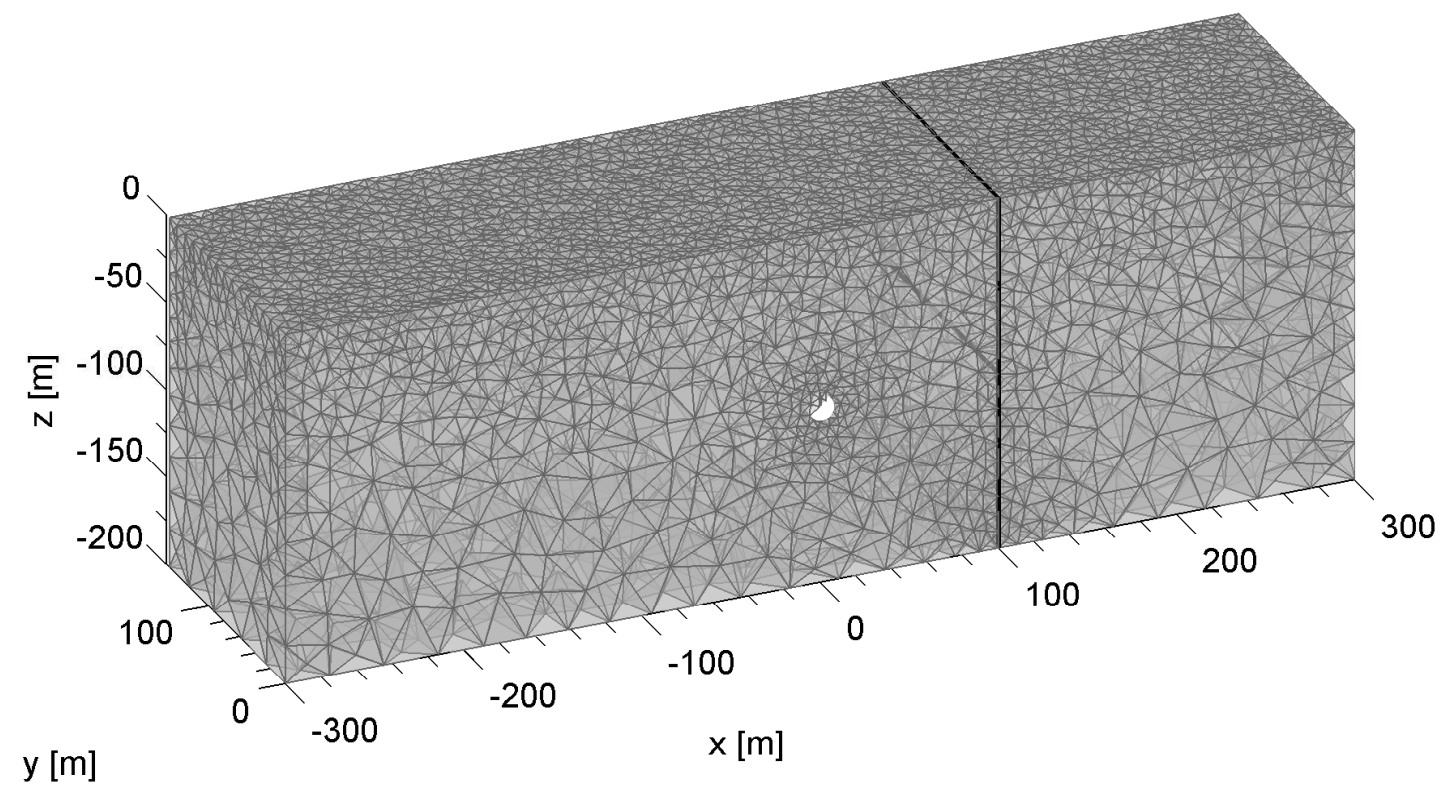

Figure 4: 3D FE model setup including the mesh. The black line at $x=100 \mathrm{~m}$ represents an interface of materials as established by a fault. The filled white circle at $z=-100 \mathrm{~m}$ marks the position of the well screen. Outer boundaries at the bottom, the right and left sides and the back (not shown) are extended to ten times the dimension of the shown block in order to minimise the influence of boundary conditions. 

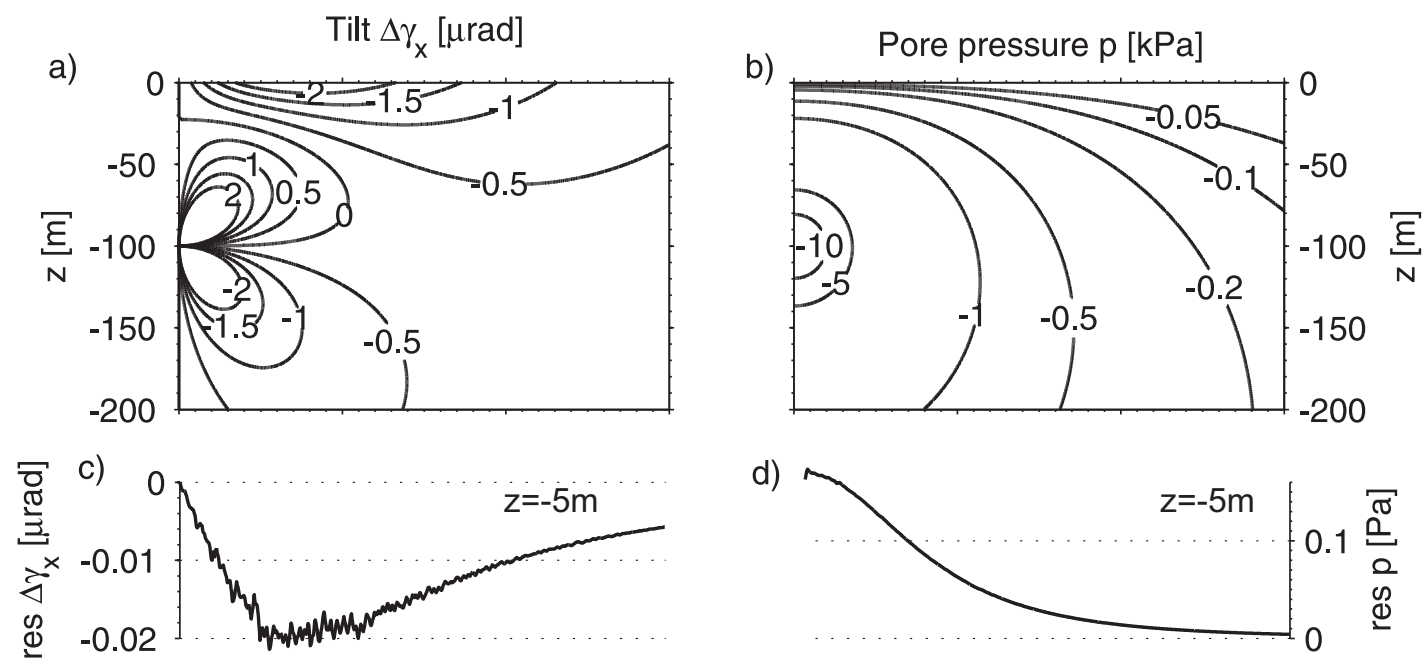

d)
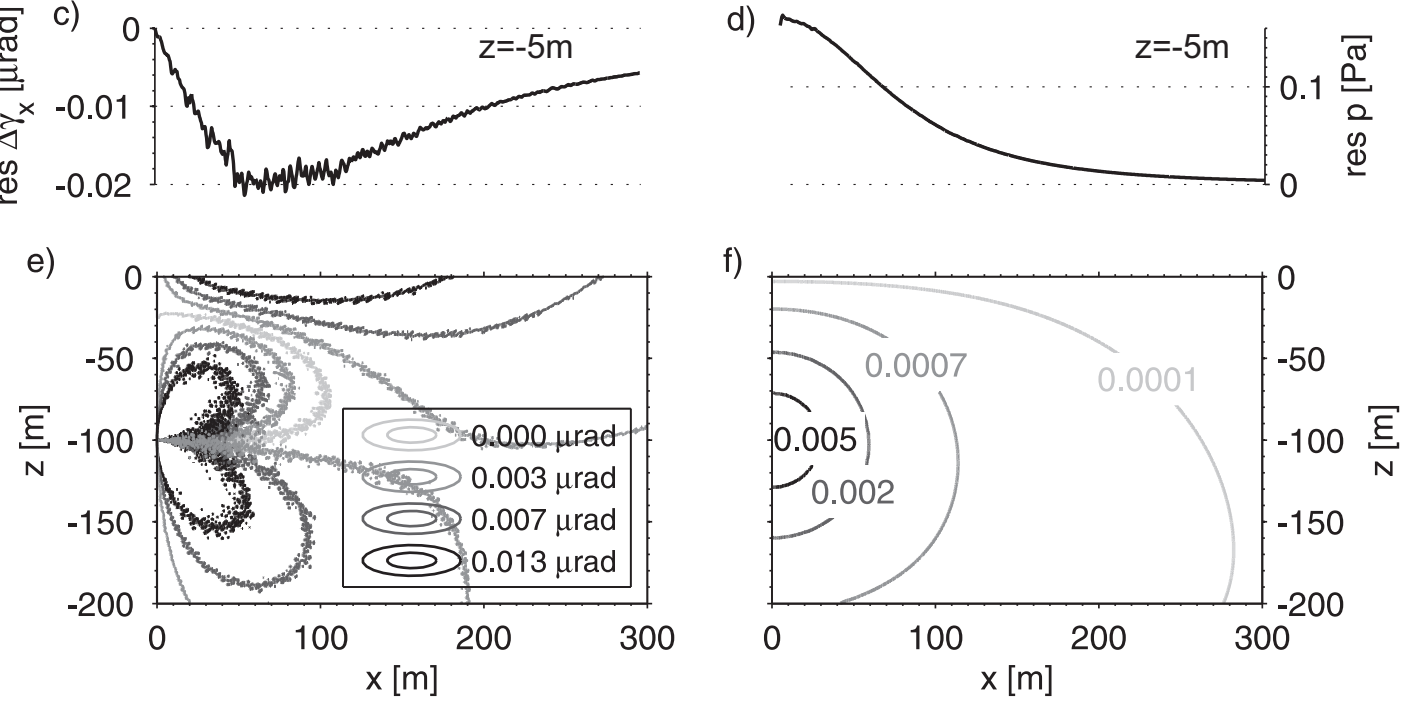

Figure 5: Analytical solution for a) tilt and b) pore pressure in a homogeneous half space of small-grained sand, near-surface residuals of the numerical solution for c) tilt and d) pore pressure and residuals in the whole model area (e, f). Tilt and pore pressure fields are radially symmetric to the vertical well axis at $\mathrm{x}=0$. Contours for a) and e) are given in $\mu \mathrm{rad}$ and for $\mathrm{b}$ ) and $\mathrm{f}$ ) in $k P a / m$. The maximum element size that is used to obtain the numerical solution is $5 \mathrm{~m}$. 

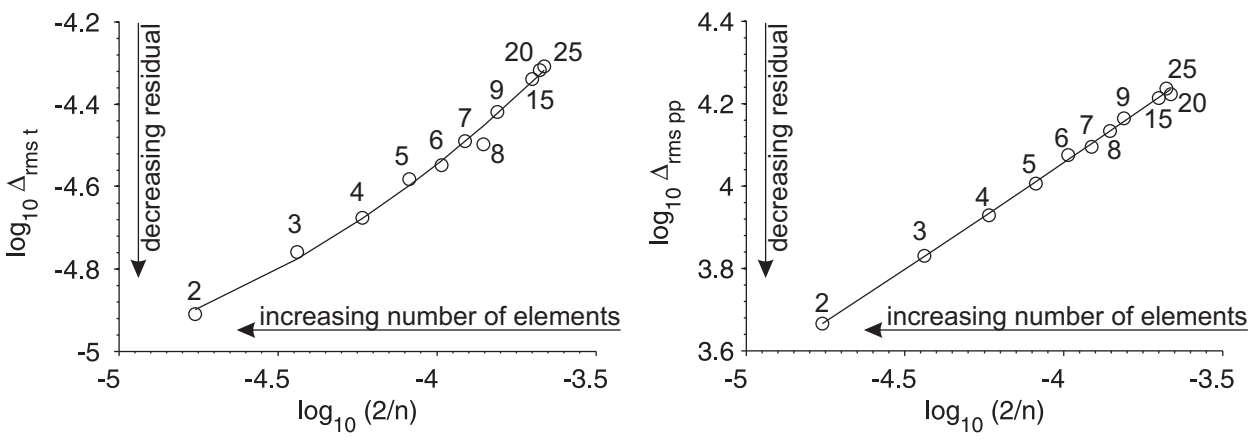

Figure 6: Convergence function of numerical solution towards analytical solution for tilt (left) and pore pressure (right) with a double logarithmic scale. Numbers next to the graph symbols indicate the maximum element size in meter, $\mathrm{n}$ is the number of elements, $\delta_{r m s t}$ and $\delta_{r m s p p}$ are the root mean square errors for tilt in rad and pore pressure in $\mathrm{Pa}$, respectively. 

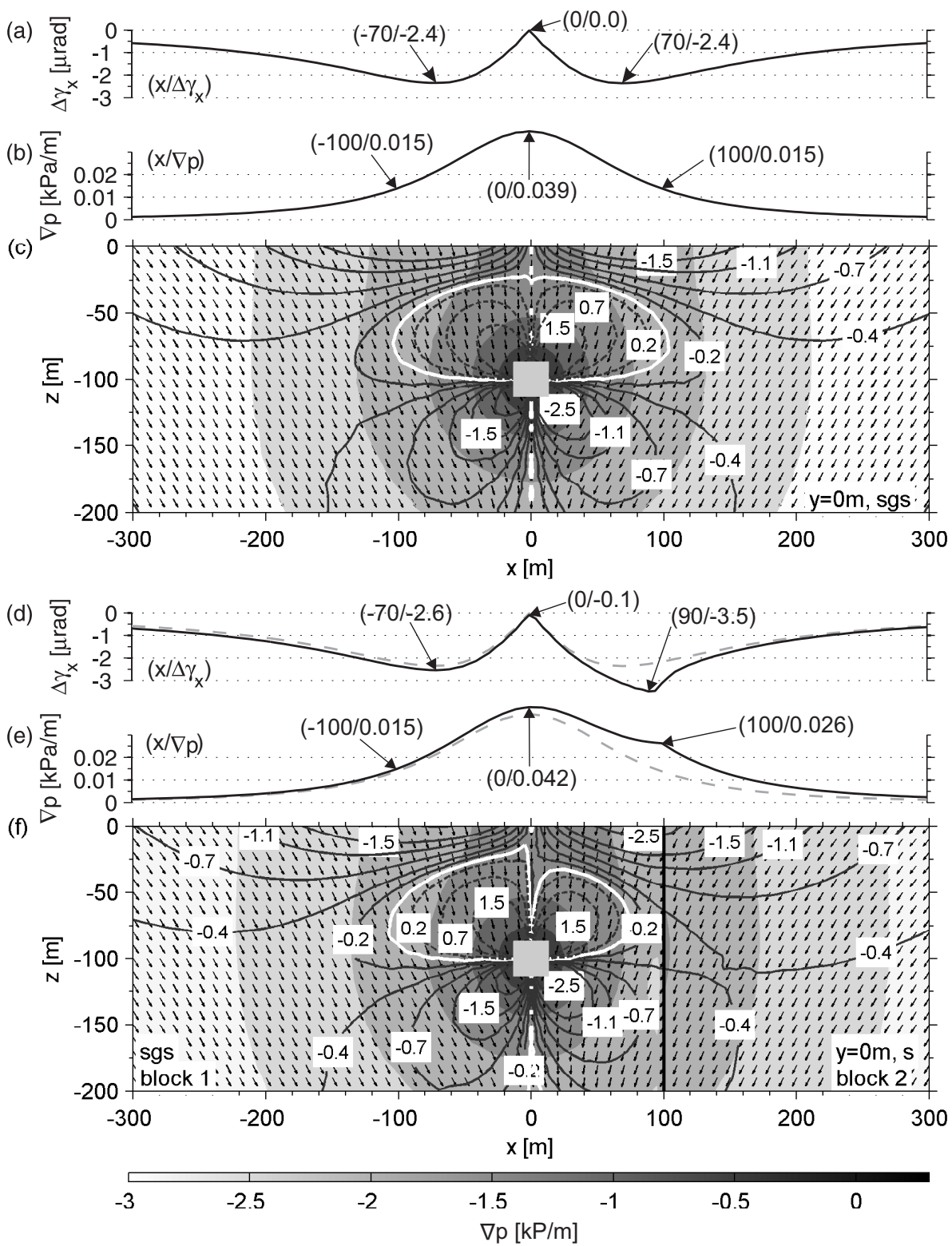

Figure 7: Solution for 3D FE models of a homogeneous half space of small-grained sand as reference (a-c) and a half space of small-grained sand (sgs, block 1) with an interface to silt (s, block 2) (d-f). (a) $\Delta \gamma_{x}$ and (b) $\nabla p$ along the surface with annotations of x-coordinate and amplitude in $\mu \mathrm{rad}$ and $\mathrm{kPa} / \mathrm{m}$ at important features, (c) x-z slice at $y=0 \mathrm{~m}$ showing pore pressure gradient (grey-scale), $\Delta \gamma_{x}$ (black contour lines with labels annotated in $\mu \mathrm{rad}$ and dashed lines indicating positive values), zero tilt (white contour line) and the direction of deformation (black vectors). At the position of the well tilt and pore pressure cannot be calculated accurately, so that this area is shaded off. (d-f) have the same notation as (a-c). Surface tilt and pore pressure gradient $\$$ shown in (a) and (b) are plotted in (d) and (e) as grey dashed lines. 

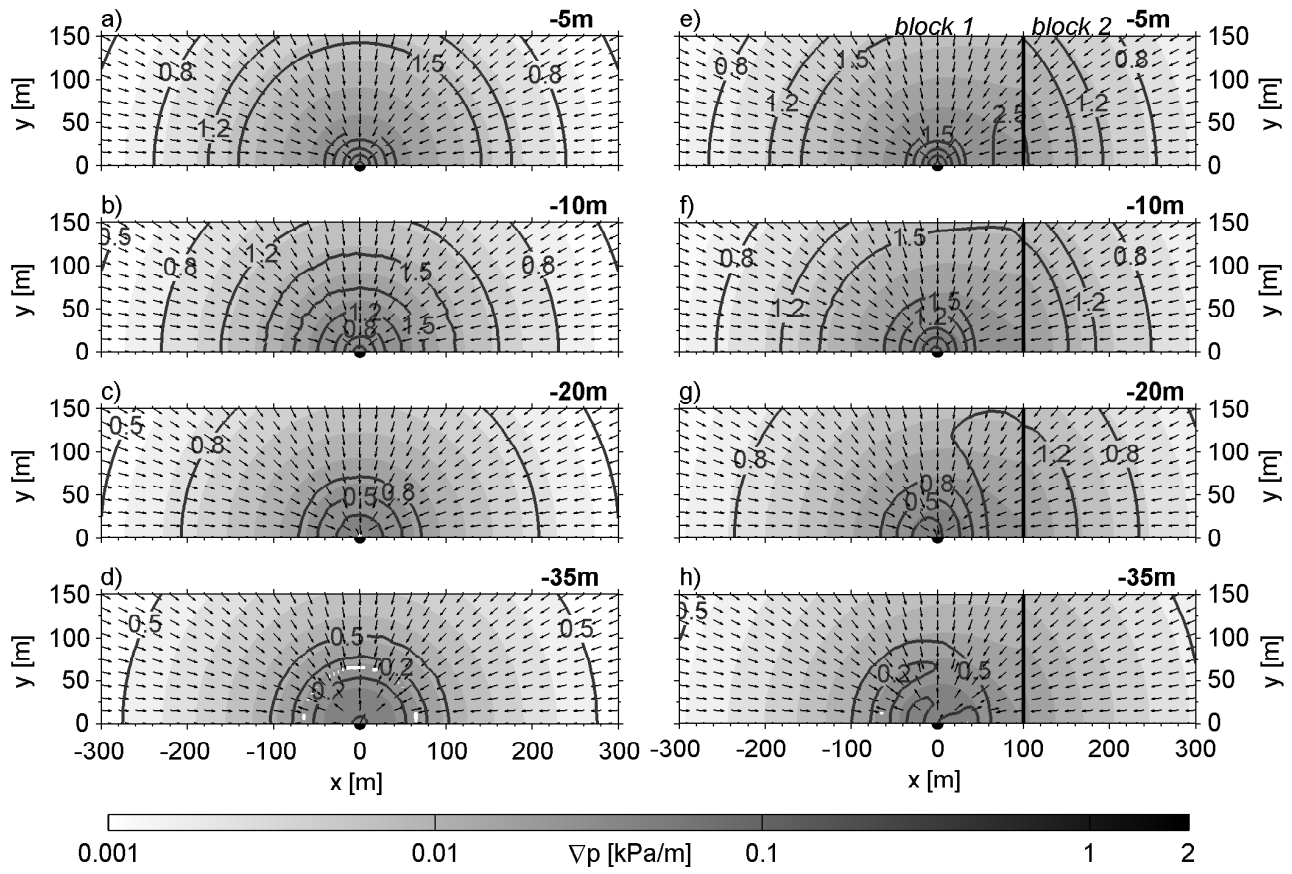

Figure 8: Horizontal slices at selected depths (x-y planes) showing total tilt $\Delta \gamma$ (contour lines), deformation direction (arrows) and pore pressure gradient (grey-scale) at depths of $z=-5 m(\mathrm{a}, \mathrm{e}),-10 m(\mathrm{~b}, \mathrm{f}),-20 m(\mathrm{c}, \mathrm{g})$ and $-35 m(\mathrm{~d}, \mathrm{~h})$. The slices on the left side (a-d) are from the homogeneous half space model of small-grained sand (Fig. 7(a-c)). The slices on the right side $(\mathrm{e}-\mathrm{h})$ are from the half space model with vertical interface (Fig. 7(d-f)). The dot at $x=y=0 m$ marks the position of the well's vertical axis. 


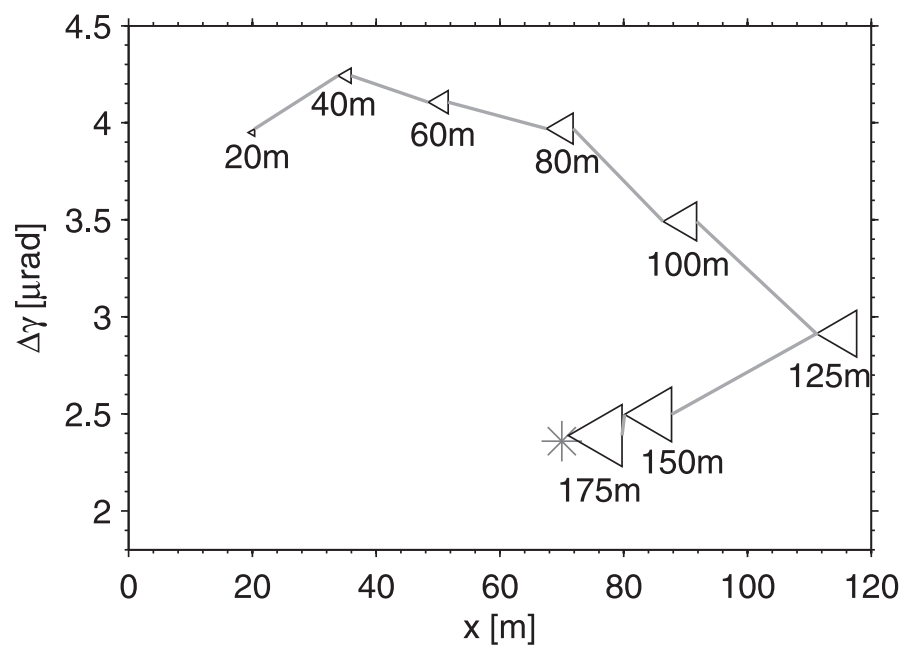

Figure 9: Amplitudes of surface tilt maxima plotted by left-pointing triangles versus their x coordinates at $y=0 \mathrm{~m}$ for models with a vertical interface (as in Fig. 7(d-f)), but at different distances from the well. The distance between the interface and the well is given below each icon. The asterisk marks the tilt maximum in the homogeneous half space.

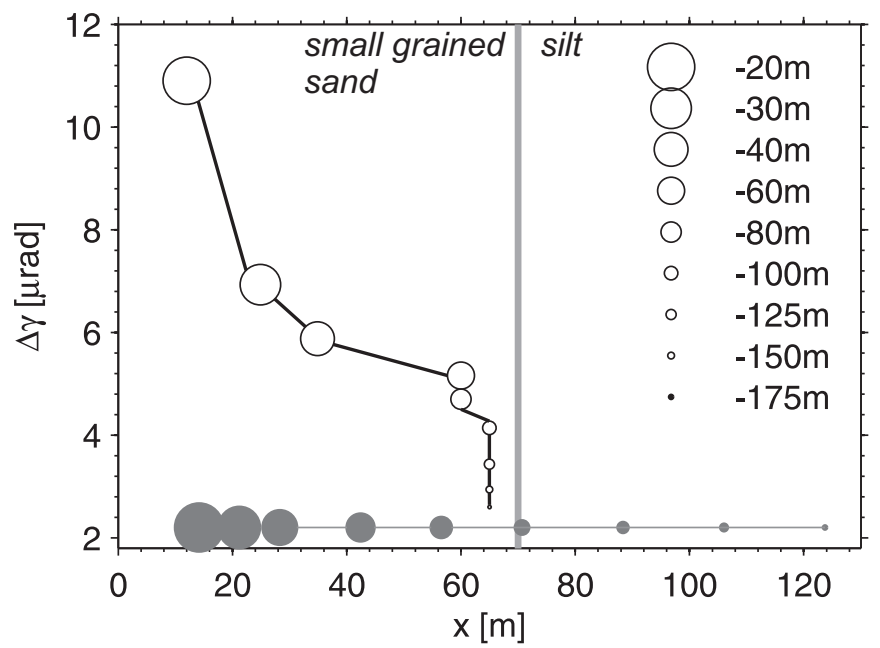

Figure 10: Amplitudes of surface tilt maxima plotted by black circles versus their x coordinates at $y=0 \mathrm{~m}$ for models with a vertical interface (as in Fig. 7(d-f)), but with different well depths. Filled grey circles show positions of the tilt maxima in a homogeneous half space. Due to illustration reasons the amplitudes for the homogeneous half spaces are manually set to a uniform value of $2.3 \mu \mathrm{rad}$. The size of the circles indicates the well depth. The interface's position is marked by a grey line. 
(a)

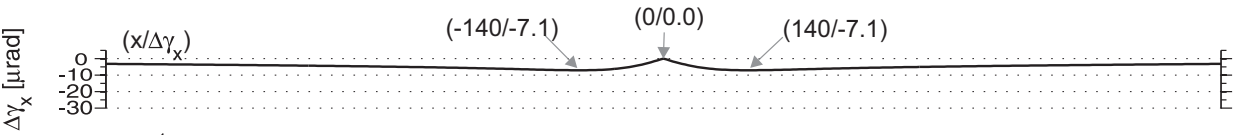

(b)

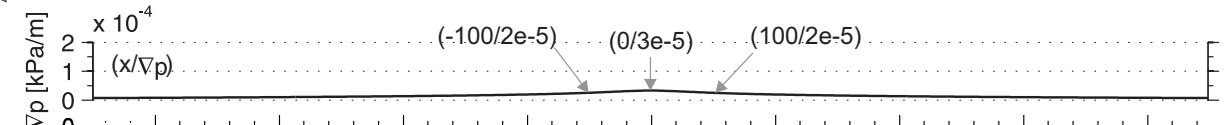

(c)

$\triangleright^{2} 0$ g.

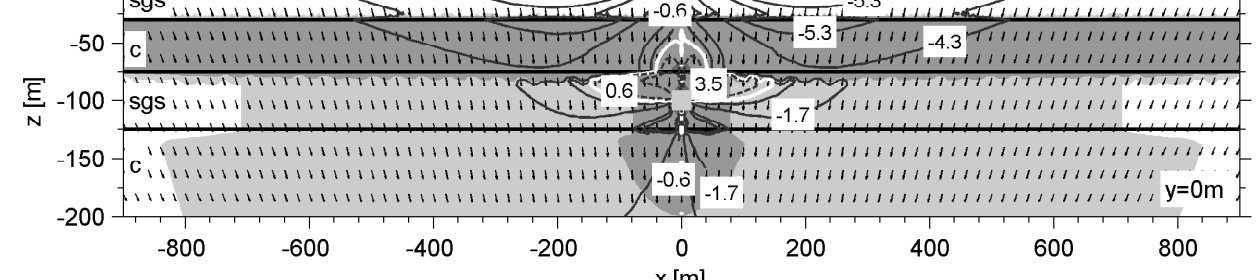

(d)

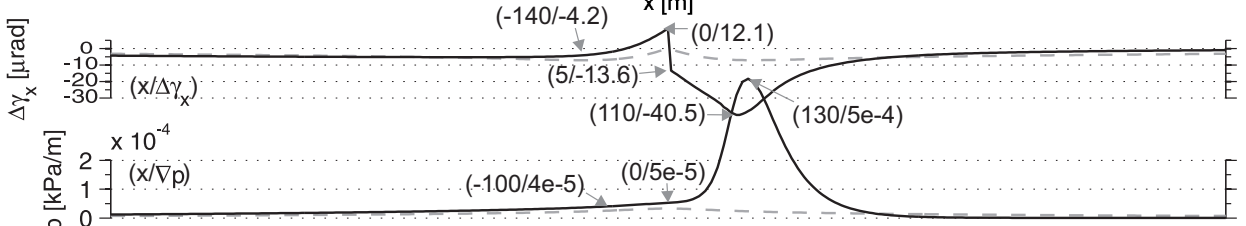

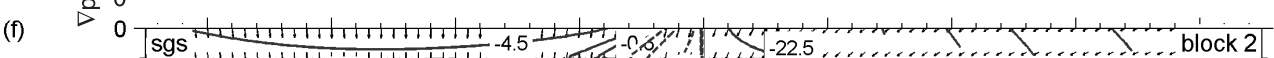

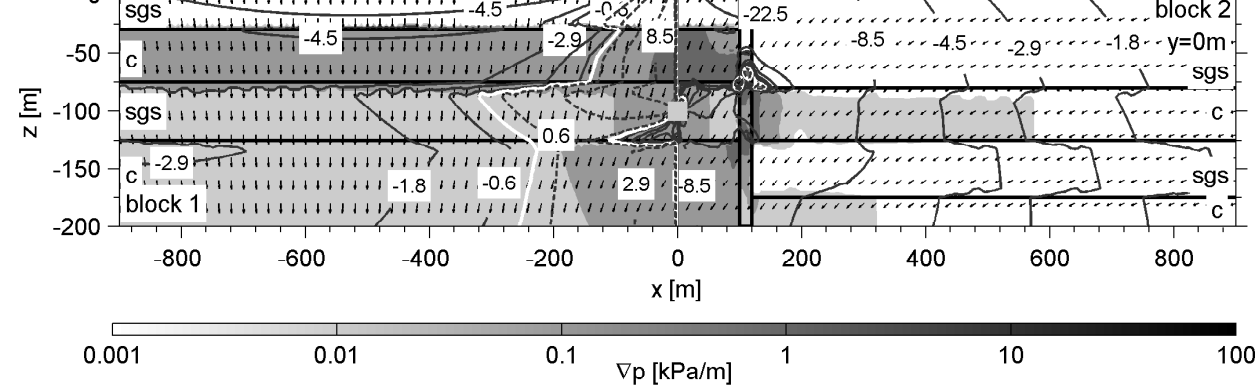

Figure 11: Solution for 3D FE models of a layered half space (a-c, see also geometry in Fig. 2(a))and a layered half space that is horizontally interrupted between $x=100 \mathrm{~m}$ and $x=120 \mathrm{~m}$ and vertically displaced by a $20 \mathrm{~m}$ wide fault zone (d-f, geometry as in Fig. 2(a)). Abbreviations for sediment types: sgs; small grained sand, c; clay. The representation is as for Fig. 7: (a,d) $\Delta \gamma_{x}$ and (b, e) $\nabla p$ along the surface, (c, f) x-z slice at $y=0 m$ showing pore pressure gradient (grey-scale), $\Delta \gamma_{x}$ (contour lines in $\mu \mathrm{rad}$, dashed lines show positive values) and the direction of deformation (black vectors). It should be noted that $2 \mathrm{D}$ slices are vertically exaggerated. 

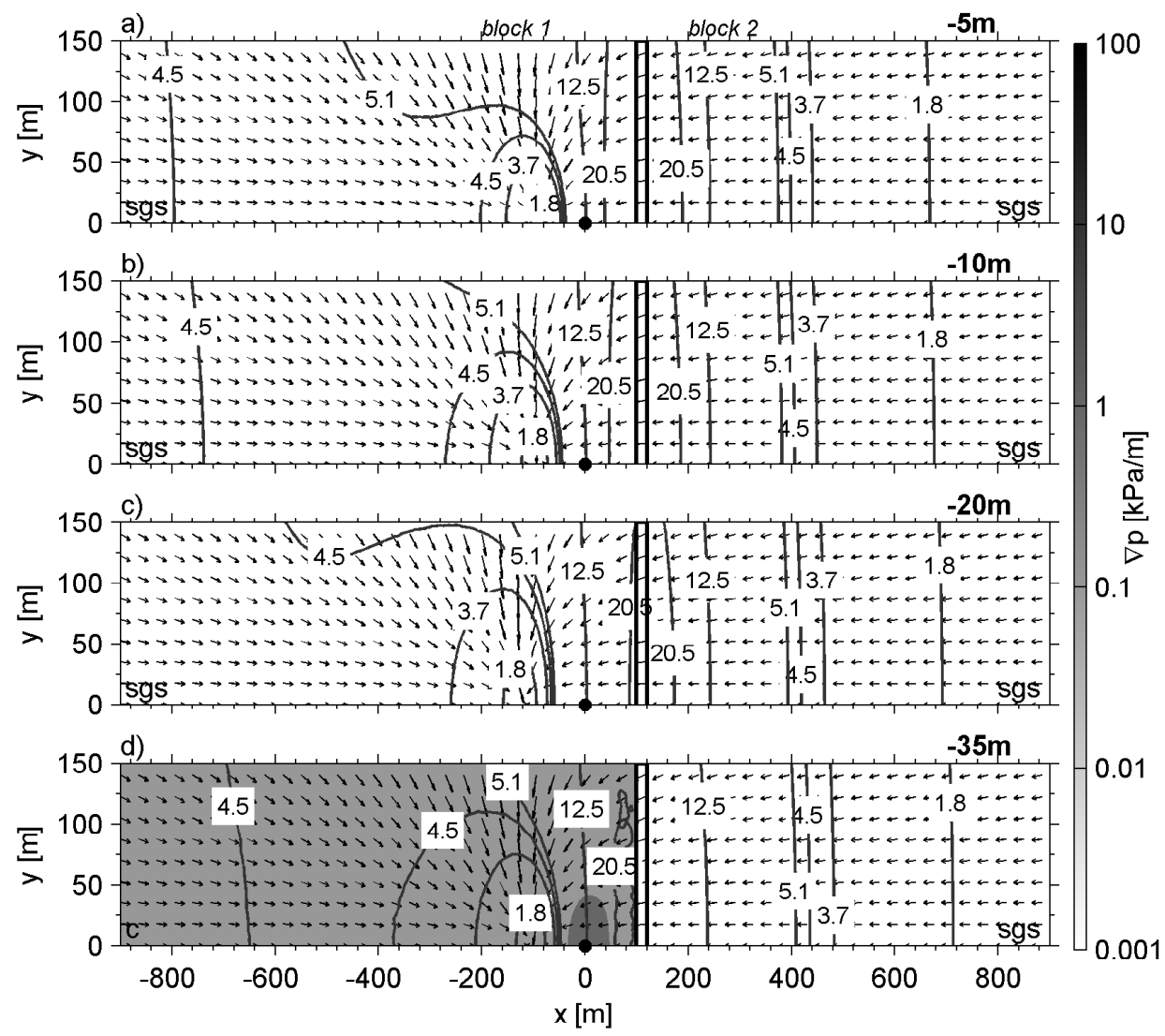

Figure 12: Horizontal slices at selected depths (x-y planes) of the four layer model with a vertical fault zone (Fig. 11(f)). Descriptions and symbols are as in Fig. 8. Numbers give the layer in which the slice is located. It should be noted that the slices are exaggerated in the y-direction. 


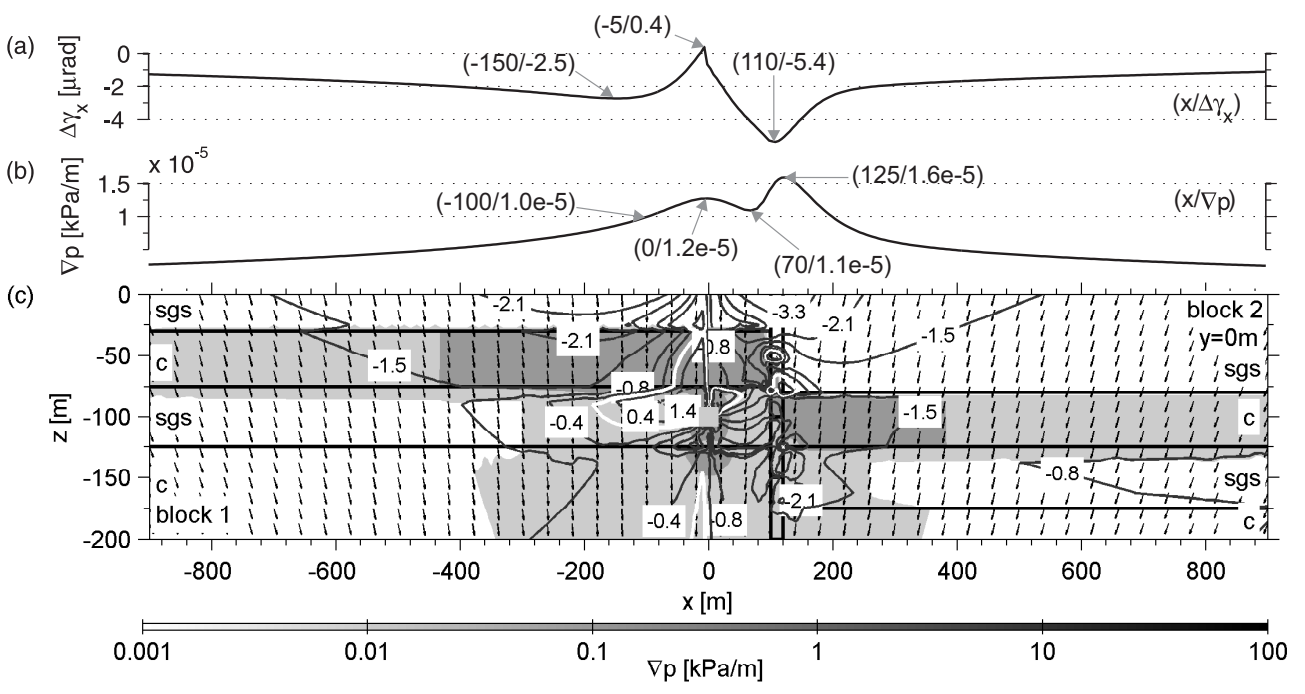

Figure 13: Solution for 3D FE models for a model of a layered half space with a fault zone with a two step fracture (Fig. 2(c)). Notations are identically to those used in Fig. 11. Slices are vertically exaggerated. 

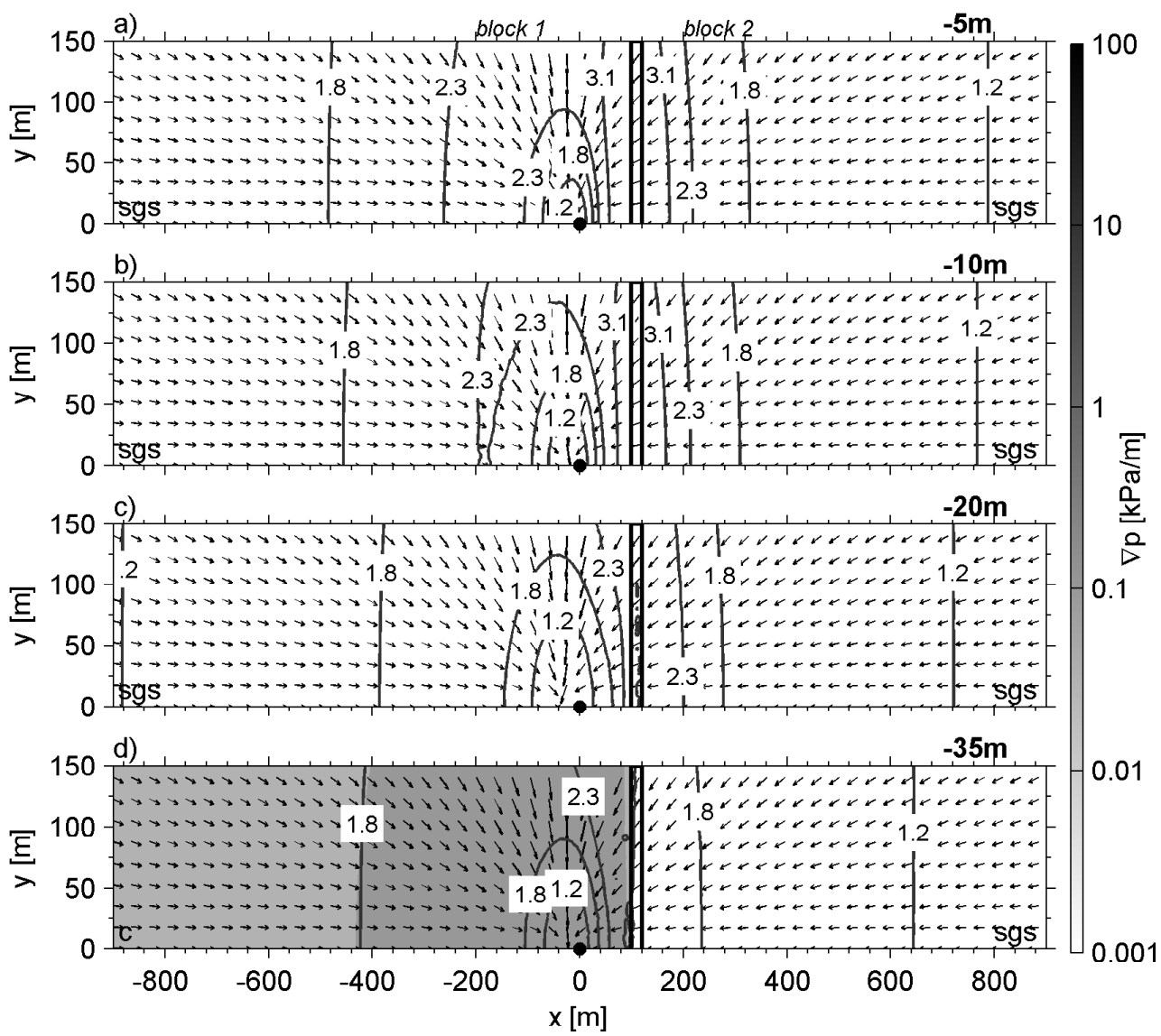

Figure 14: Horizontal slices at selected depths for the model also shown in Fig. 13(b). Notations are identically to those used in Fig. 8. Slices are exaggerated in the y-direction. 